TITLE:

\title{
Caspase-mediated cleavage of phospholipid flippase for apoptotic phosphatidylserine exposure.
}

\section{AUTHOR(S):}

Segawa, Katsumori; Kurata, Sachiko; Yanagihashi, Yuichi; Brummelkamp, Thijn R; Matsuda, Fumihiko; Nagata, Shigekazu

\section{CITATION:}

Segawa, Katsumori ...[et al]. Caspase-mediated cleavage of phospholipid flippase for apoptotic phosphatidylserine exposure.. Science 2014, 344(6188): 1164-1168

\section{ISSUE DATE:}

2014-06-06

URL:

http://hdl.handle.net/2433/189106

\section{RIGHT:}

(c) 2014 by the American Association for the Advancement of Science; こ の論文は出版社版でありません。引用の際には出版社版をご確認ご利 用ください。; This is not the published version. Please cite only the published version. 


\section{Title: Caspase-mediated cleavage of phospholipid flippase for apoptotic phosphatidylserine exposure}

Authors: Katsumori Segawa ${ }^{1}$, Sachiko Kurata ${ }^{1}$, Yuichi Yanagihashi ${ }^{1}$, Thijn R. Brummelkamp ${ }^{2}$, Fumihiko Matsuda $^{3}$, and Shigekazu Nagata ${ }^{1,4^{*}}$

${ }^{1}$ Department of Medical Chemistry and ${ }^{3}$ Center for Genomic Medicine, Graduate School of Medicine, Kyoto University, Yoshida-Konoe, Kyoto 606-8501, Japan.

${ }^{2}$ Netherlands Cancer Institute, Plesmanlaan 121, 1066 CX Amsterdam, Netherlands.

${ }^{4}$ Core Research for Evolutional Science and Technology, Japan Science and Technology Corporation, Kyoto 606-8501, Japan.

*Correspondence to: E-mail: snagata@mfour.med.kyoto-u.ac.jp

Title: 92 characters

Abstract: 124 words

Text + References + Legends: 2577 words 
Phospholipids are asymmetrically distributed in the plasma membrane. This asymmetrical distribution is disrupted during apoptosis, exposing phosphatidylserine (PtdSer) on the cell surface. Here, using a haploid genetic screen we found that ATP11C (ATPase, type 11C) and CDC50A (Cell division cycle protein 50A) are required for aminophospholipid translocation from the outer to inner plasma-membrane leaflet (flippase activity). ATP11C contained caspaserecognition sites, and mutations at these sites generated caspase-resistant ATP11C without affecting its flippase activity. Cells expressing caspase-resistant ATP11C did not expose PtdSer during apoptosis, and were not engulfed by macrophages, suggesting that inactivation of the flippase activity is required for apoptotic PtdSer exposure. $C D C 50 A$-deficient cells displayed PtdSer on their surface, and were engulfed by macrophages, indicating that PtdSer is sufficient as an "eat me" signal.

One Sentence Summary: Identification of a caspase-regulated flippase for the asymmetrical distribution of phospholipids in the plasma membrane. 
In eukaryotic cells, phospholipids are asymmetrically distributed between the outer and inner leaflets of the plasma membrane (1). Phosphatidylcholine [PtdCho] and sphingomyelin are located primarily in the outer leaflet, while phosphatidylserine [PtdSer], and phosphatidylethanolamine [PtdEtn] are restricted to the cytoplasmic leaflet. Disruption of asymmetrical phospholipid distribution, in particular, cell-surface PtdSer exposure, is important in various biological processes. For example, platelet activation leads to PtdSer exposure to activate clotting factors (1), and apoptotic cells expose PtdSer to be engulfed by phagocytes (2). Scramblases non-specifically transport phospholipids bidirectionally (1). TMEM16F is essential for PtdSer-exposure in activated platelets (3), while Xkr8 (XK-related protein 8) supports the phospholipid scrambling after being cleaved by caspase during apoptosis (4). Flippases transport aminophospholipids from the extracellular to cytoplasmic side (1). Some members (mammalian ATP8A1 and its orthologs in yeast and C. elegans, and ATP11C) of the Type 4 subfamily of Ptype ATPases (P4-ATPase) have been proposed to act as flippases (5-8). Earlier studies reported that the flippase is inactivated during apoptosis $(9,10)$, but, its identity and how it is inactivated is unclear.

We used a haploid genetic screen in human KBM7 cells (11) to identify the plasma membrane PtdSer flippase. KBM7 cells incorporated 1-oleoyl-2-\{6-[(7-nitro-2-1,3benzoxadiazol-4-yl)amino]hexanoyl\}-sn-glycero-3-PtdSer (NBD-PS), NBD-PtdEtn (NBD-PE) and NBD-PtdCho (NBD-PC) with different efficiencies (Fig. 1A). KBM7 cells were mutagenized with a gene trap vector. Approximately $1.0 \%$ of the cells defective in NBD-PS internalization were expanded, and subjected to a second sorting step to obtain "Low Flipping" cells (LF)(Fig. 1B). Gene-trap insertion sites were recovered by polymerase chain reaction from LF cells, and identified by deep sequencing (12). Proximity index, for genomic regions 
containing multiple insertions in close proximity, identified two genes (CDC50A, Cell division cycle protein 50A, and ATP11C, ATPase type 11C) (Fig. 1B). Based on the information from genome database (http://genome.ucsc.edu/cgi-bin/hgTracks?org=human) and 5'-RACE (Rapid amplification of cDNA end) analysis (fig. S1), most of the insertions were assigned to intron 1 in the transcriptional direction (Fig. 1C).

ATP11C is a member of P4-ATPase family, and CDC50A is its $\beta$-subunit (Fig. S2A) (13, 14). They were expressed in various tissues (Fig. S2B). Cloned cell lines (ATP11C ${ }^{\mathrm{GT}}$ and $\mathrm{CDC}_{50 \mathrm{~A}^{\mathrm{GT}}}$ ) that lost the expression of $A T P 11 C$ or $C D C 50 A$ (Fig. S2C) were isolated. The ability to incorporate NBD-PS and NBD-PE, but not NBD-PC was reduced in ATP11C ${ }^{\mathrm{GT}}$ and the transformation with human (h)ATP11C rescued it (Fig. 1D). The incorporation of phospholipids in ATP11C $\mathrm{C}^{\mathrm{GT}}$ was inhibited by orthovanadate (Fig. 1E), suggesting that the remaining flippase activity was due to other P4-ATPases in KBM7 cells (Fig. S2D). Among three members, only CDC50A was expressed in KBM7 cells (Fig. S2D), and the internalization of NBD-PS was completely defective in $\mathrm{CDC} 0 \mathrm{~A}^{\mathrm{GT}}$, which was rescued with hCDC50A (Fig. 1D). CDC50A $\mathrm{A}^{\mathrm{GT}}$, but not ATP11C $\mathrm{C}^{\mathrm{GT}}$ exposed PdtSer on the cell surface (Fig. 1F), suggesting that the residual PtdSer-flippase in ATP11 $\mathrm{C}^{\mathrm{GT}}$ was sufficient to maintain the asymmetrical PtdSer distribution. The ability to internalize NBD-PC was also reduced in CDC50A ${ }^{\mathrm{GT}}$ (Fig. 1D), indicating that some P4-ATPases in KBM7 cells may promote PtdCho flipping.

To study the effect of the PtdSer-flippase on apoptotic PtdSer, we chose W3 cells that undergo apoptosis upon treatment with Fas ligand (FasL)(15). W3 cells expressed several P4ATPases (fig. S3A), and incorporated NBD-PS, NBD-PE and NBD-PC with different efficiencies (fig. S3B). ATP11C in W3 cells was mutated using the CRISPR/Cas (clustered regulatory interspaced short palindromic repeats/CRISPR associated) system (16) (fig. S3C). 
Two cloned cell lines (ATP11C $\mathrm{ED}^{\mathrm{E} 22}$ and ATP11C $\mathrm{ED}^{\mathrm{E} 23}$ ) carrying biallelic ATP11C truncations lost the ability to internalize NBD-PS and NBD-PE (Fig. 2A and fig. S3D). Apoptotic PtdSer exposure is accompanied by the loss of PtdSer-flippase activity $(9,10)$. Treating W3 cells with FasL reduced ATP11C from 120 to $50 \mathrm{kDa}$ (Fig. 2B), which was prevented by a caspase inhibitor (Q-VD-OPh). A search using Cascleave (http://sunflower.kuicr.kyotou.ac.jp/ sjn/Cascleave/) revealed three caspase-recognition sequences (Sites 1-3) in the Nucleotide-binding or "N" domain of hATP11C (fig. S4A). Mutants in Sites 1-3 were generated (fig. S4B), tagged by Green fluorescent protein (GFP) at the C-terminus, and expressed in $A T P 11 C^{E D 22}$. The transformants were treated with FasL, and analyzed by immunoblotting with anti-GFP antibodies (Fig. 2C). The FasL-treatment caused a shift of the wild-type and doubly mutated hATP11C-GFP from 140 to $80 \mathrm{kDa}$. While, little cleavage was observed with the triply mutated hATP11C-GFP (CasR). Incubation of the membrane fraction carrying hATP11C-GFP with caspases revealed that hATP11C was cleaved by caspase-3, -6 and -7 (fig. S5). ATP11C ${ }^{\text {ED22 }}$ expressing CasR (ATP11C ${ }^{\mathrm{ED} 22}$-CasR) incorporated NBD-PS as efficiently as those expressing wild-type ATP11C (ATP11C ED22-hATP11C) (Fig. 2D), and could not expose PtdSer upon FasLtreatment (Fig. 2E), although caspase-3 was activated (Fig. 2E). Transformation of W3-Ildm cells, a derivative of W3 cells (17), and human Jurkat cells with CasR, but not with wild-type hATP11C blocked the FasL-induced PtdSer-exposure (fig. S6). CasR had no effect on the FasLinduced scramblase, measured by NBD-PC incorporation (Fig. 2F). FasL-induced cell death, cell shrinkage and DNA fragmentation were also normal in CasR-expressing cells (fig. S7). The FasL-treated W3-Ildm cells and the $\mathrm{h} A T P 11 C$-transformants were efficiently engulfed by thioglycollate-elicited peritoneal macrophages (thio-pMacs), while the CasR-transformants were 
not (Fig. 2G), suggesting that the flippase must be inactivated by caspase for engulfment of apoptotic cells.

CDC50A was then mutated using the Crispr/Cas system in W3-Ildm cells that expressed only CDC50A in the CDC50 family (fig. S8A). Cloned cell lines (CDC50A ${ }^{\mathrm{ED} 29}$ and $\mathrm{CDC} 50 \mathrm{~A}^{\mathrm{ED} 62}$ ) carrying a biallelic truncation (fig. S8B) could not support the localization of hATP11C-GFP at the plasma membrane (Fig. 3A), could not internalize NBD-PS (Fig. 3B), and exposed PtdSer (Fig. 3C and fig. S9A). Transformation of CDC50A ${ }^{\mathrm{ED}}$ cells with hCDC50A supported the localization of ATP11C at the plasma membrane, rescued the flippase activity, and blocked PtdSer exposure, confirming the chaperone-like function of CDC50 for P4-ATPase (5, 13, 14). W3 cells expressing a constitutively active form of TMEM16F (D430G-L) $(3,18)$ internalized NBD-PS (Fig. 3B), bound MFG-E8, a PtdSer-binding protein (19), in HEPES buffered saline containing $2.5 \mathrm{mM} \mathrm{CaCl}_{2}$, but not in Iscove's modified Dulbecco's medium (IMDM)-10\% fetal calf serum (FCS) (Fig. 3D). In contrast, CDC50A ${ }^{\mathrm{ED}}$ cells bound MFG-E8 in IMDM-10\% FCS. Observation by microscope confirmed the binding of MFG-E8 to CDC50A ${ }^{\mathrm{ED}}$ cells. The doubling time of $\mathrm{CDC}_{0} \mathrm{~A}^{\mathrm{ED} 29}$ cells was slightly longer than W3-Ildm cells (12.2 \pm 0.39 vs. $13.7 \pm 0.14$ h) (fig. S9B), but $\mathrm{CDC}_{0} \mathrm{~A}^{\mathrm{ED} 29}$ cells responded normally to FasL for apoptosis (fig. S9C).

When living $\mathrm{CDC} 50 \mathrm{~A}^{\mathrm{ED}}$ cells were cultured with thio-pMacs in medium containing $1.0 \%$ methylcellulose, more than $20 \%$ of the macrophages engulfed CDC50A $\mathrm{A}^{\mathrm{ED}}$ cells (Fig. $4 \mathrm{~A}$ ). The thio-pMacs did not engulf W3-Ildm cells, W3-D430G-L cells, or CDC50A ${ }^{\mathrm{ED}}$-hCDC50A cells. The engulfment of CDC50A ${ }^{\mathrm{ED}}$ cells was inhibited by D89E, which masks PtdSer (19). Similar to the engulfment of apoptotic cells (20), living $\mathrm{CDC}_{00} \mathrm{~A}^{\mathrm{ED}}$ cells were not engulfed by $\mathrm{MerTK}^{-/}$ thio-pMacs (Fig. 4B). Among 132 events of engulfment (Fig. 4C and Movie S1-S2), 
approximately $80 \%$ events were with living cell, while $20 \%$ were apoptotic cells. As reported for the entosis of epithelial cells (21), the engulfment of living $\mathrm{CDC} 5 \mathrm{~A}^{\mathrm{ED}}$ cells was reversible until a certain point. Approximately $3 \%$ of the engulfed cells were released from the macrophages before they were transferred into lysosomes (Fig. 4D and Movie S3). The release of engulfed cells was not observed with caspase-positive cells. Examination with electron microscopy showed that the engulfed living cells had a swollen morphology (Fig. 4E), different from the apoptotic cells with a condensed morphology. Engulfment of living PtdSer-exposing cells by thio-pMacs was also observed with $C D C 50 A$-null KBM7 cells (fig. S10). Subcutaneous transplantation of W3-Ildm cells into nude mice induced tumors in 8 of 11 recipients, and the tumor size was approximately $4.3 \mathrm{~g}$ after 4 weeks (Fig. 4F). $\mathrm{CDC}_{0} \mathrm{~A}^{\mathrm{ED}}$, but not its hCDC50Atransformants, lost the ability to develop tumors, suggesting that $\mathrm{CDC} 50 \mathrm{~A}^{\mathrm{ED}}$ was cleared in vivo.

Here we have shown that ATP11C can function as a PtdSer-flippase at the plasma membrane. ATP11C-deficient KBM7 cells and W3 cells exhibited reduced PtdSer-flippase activity, while $C D C 50 A$-null cells almost completely lost the activity. Most, if not all, P4ATPases require CDC50 family proteins as a functional subunit or chaperone (5, 22, 23). KBM7 cells and W3 cells expressed only CDC50A among CDC50 proteins, but expressed ATP11C and other P4-ATPases, some of which may also function as a PtdSer-flippase. PtdSer-flippase has been considered to be specific for aminophospholipids (14). But, as reported previously with Jurkat cells (24), CDC50A-null KBM7 cells lost the ability to transport PtdCho, suggesting that some P4-ATPases may flip PtdCho. In apoptosis, Xkr8's scramblase is activated (4) and ATP11C's flippase is inactivated to expose PtdSer. The PtdSer exposure in activated platelets and lymphocytes is $\mathrm{Ca}^{2+}$-dependent $(3,25)$. Because a high $\mathrm{Ca}^{2+}$ concentration inhibits $\mathrm{P} 4-$ ATPases (26), PtdSer exposure in these processes may be mediated by the $\mathrm{Ca}^{2+}$-dependent 
activation of scramblases coupled to the $\mathrm{Ca}^{2+}$-mediated down-regulation of flippase activity. Once cellular $\mathrm{Ca}^{2+}$ levels are reduced, ATP11C and/or other P4-ATPases would re-establish the asymmetric phospholipid distribution in the plasma membrane. On the other hand, caspasemediated apoptotic PtdSer exposure is irreversible, leading to engulfment by macrophages.

The engulfment of living cells by neighboring cells or macrophages has been reported in various systems $(21,27,28)$. Our results, the engulfment of PtdSer-exposing CDC50A-null cells by macrophages, support the idea (28) that when PtdSer is exposed, even viable cells can be engulfed. The engulfment of living cells may be involved in various diseases, such as hemophagocytosis, neurodegeneration, and cancer (29). ATP $11 C$-defective mice lose a large number of B cells during Pro to Pre-B cell differentiation in bone marrow (7, 30), and a weak defect in the PtdSer internalization has been detected in Pro-B cells (7). One possible explanation is that among the P4-ATPases promoting flippase activity, only ATP11C is expressed in the early stage of B cell development. Thus, ATP11C-defective cells expose PtdSer and are engulfed by macrophages. 


\section{References and Notes:}

1. P. A. Leventis, S. Grinstein, The distribution and function of phosphatidylserine in cellular membranes. Annu. Rev. Biophys. 39, 407-427 (2010).

doi:10.1146/annurev.biophys.093008.131234

2. S. Nagata, R. Hanayama, K. Kawane, Autoimmunity and the clearance of dead cells. Cell 140, 619-630 (2010). doi:10.1016/j.cell.2010.02.014

3. J. Suzuki, M. Umeda, P. J. Sims, S. Nagata, Calcium-dependent phospholipid scrambling by TMEM16F. Nature 468, 834-838 (2010). doi:10.1038/nature09583

4. J. Suzuki et al., Xk-related protein 8 and CED-8 promote phosphatidylserine exposure in apoptotic cells. Science 341, 403-406 (2013). doi:10.1126/science.1236758

5. K. Tanaka, K. Fujimura-Kamada, T. Yamamoto, Functions of phospholipid flippases. J. Biochem. 149, 131-143 (2011). doi:10.1093/jb/mvq140

6. X. Tang, M. S. Halleck, R. A. Schlegel, P. Williamson, A subfamily of P-type ATPases with aminophospholipid transporting activity. Science 272, 1495-1497 (1996).

7. M. Yabas et al., ATP11C is critical for the internalization of phosphatidylserine and differentiation of B lymphocytes. Nat. Immunol. 12, 441-449 (2011). doi:10.1038/ni.2011

8. T. T. Sebastian, R. D. Baldridge, P. Xu, T. R. Graham, Phospholipid flippases: building asymmetric membranes and transport vesicles. Biochimi. Biophys. Acta 1821, 1068-1077 (2012). doi:10.1016/j.bbalip.2011.12.007

9. B. Verhoven, R. A. Schlegel, P. Williamson, Mechanisms of phosphatidylserine exposure, a phagocyte recognition signal, on apoptotic T lymphocytes. J. Exp. Med. 182, 15971601 (1995).

10. D. L. Bratton et al., Appearance of phosphatidylserine on apoptotic cells requires 
calcium-mediated nonspecific flip-flop and is enhanced by loss of the aminophospholipid translocase. J. Biol. Chem. 272, 26159-26165 (1997). doi:10.1074/jbc.272.42.26159

11. M. Kotecki, P. S. Reddy, B. H. Cochran, Isolation and characterization of a near-haploid human cell line. Exp. Cell Res. 252, 273-280 (1999). doi:10.1006/excr.1999.4656

12. J. E. Carette et al., Global gene disruption in human cells to assign genes to phenotypes by deep sequencing. Nat. Biotechnol. 29, 542-546 (2011). doi:10.1038/nbt.1857

13. H. Takatsu et al., ATP9B, a P4-ATPase (a Putative Aminophospholipid Translocase), Localizes to the trans-Golgi Network in a CDC50 Protein-independent Manner. J. Biol. Chem. 286, 38159-38167 (2011). doi:10.1074/jbc.M111.281006

14. J. A. Coleman, F. Quazi, R. S. Molday, Mammalian P4-ATPases and ABC transporters and their role in phospholipid transport. BBA - Mol. Cell Biol. L. 1831, 555-574 (2013). doi:10.1016/j.bbalip.2012.10.006

15. M. Tanaka et al., Lethal effect of recombinant human Fas ligand in mice pretreated with Propionibacterium acnes. J. Immunol. 158, 2303-2309. (1997).

16. L. Cong et al., Multiplex Genome Engineering Using CRISPR/Cas Systems. Science 339, 819-823 (2013). doi:10.1126/science.1231143

17. H. Sakahira, M. Enari, S. Nagata, Cleavage of CAD inhibitor in CAD activation and DNA degradation during apoptosis. Nature 391, 96-99 (1998). doi:10.1038/34214

18. K. Segawa, J. Suzuki, S. Nagata, Constitutive exposure of phosphatidylserine on viable cells. Proc. Natl. Acad. Sci. USA 108, 19246-19251 (2011).

doi:10.1073/pnas. 1114799108

19. R. Hanayama et al., Identification of a factor that links apoptotic cells to phagocytes. Nature 417, 182-187 (2002). doi:10.1038/417182a 
20. H. M. Seitz et al., Macrophages and dendritic cells use different Axl/Mertk/Tyro3 receptors in clearance of apoptotic cells. J. Immunol. 178, 5635-5642 (2007). doi:10.4049/jimmunol.178.9.5635

21. M. Overholtzer et al., A nonapoptotic cell death process, entosis, that occurs by cell-incell invasion. Cell 131, 966-979 (2007). doi:10.1016/j.cell.2007.10.040

22. B. Chen et al., Endocytic sorting and recycling require membrane phosphatidylserine asymmetry maintained by TAT-1/CHAT-1. PLoS Genet. 6, e1001235 (2010). doi:10.1371/journal.pgen.1001235

23. L. M. van der Velden et al., Heteromeric interactions required for abundance and subcellular localization of human CDC50 proteins and class 1 P4-ATPases. J. Biol. Chem. 285, 40088-40096 (2010). doi:10.1074/jbc.M110.139006

24. R. Chen, E. Brady, T. M. McIntyre, Human TMEM30a promotes uptake of antitumor and bioactive choline phospholipids into mammalian cells. J. Immunol. 186, 3215-3225 (2011). doi:10.4049/jimmunol.1002710

25. J. I. Elliott et al., Membrane phosphatidylserine distribution as a non-apoptotic signalling mechanism in lymphocytes. Nat. Cell Biol. 7, 808-816 (2005). doi:10.1038/ncb1279

26. D. L. Daleke, J. V. Lyles, Identification and purification of aminophospholipid flippases. Biochim. Biophys. Acta 1486, 108-127 (2000). doi:10.1016/S1388-1981(00)00052-4

27. P. A. Oldenborg et al., Role of CD47 as a marker of self on red blood cells. Science 288, 2051-2054 (2000). doi:10.1126/science.288.5473.2051

28. M. Darland-Ransom et al., Role of C. elegans TAT-1 protein in maintaining plasma membrane phosphatidylserine asymmetry. Science 320, 528-531 (2008). doi:10.1126/science. 1155847 
29. G. C. Brown, J. J. Neher, Eaten alive! Cell death by primary phagocytosis: 'phagoptosis'. Trends Biochem. Sci. 37, 325-332 (2012). doi:10.1016/j.tibs.2012.05.002

30. O. M. Siggs, B. Schnabl, B. Webb, B. Beutler, X-linked cholestasis in mouse due to mutations of the P4-ATPase ATP11C. Proc. Nat. Acad. Sci. USA 108, 7890-7895 (2011). doi:10.1073/pnas.1104631108

31. Q. Lu et al., Tyro-3 family receptors are essential regulators of mammalian spermatogenesis. Nature 398, 723-728 (1999). doi:10.1038/19554

32. R. Watanabe-Fukunaga et al., Lymphoproliferation disorder in mice explained by defects in Fas antigen that mediates apoptosis. Nature 356, 314-317 (1992).

33. T. Kitamura, New experimental approaches in retrovirus-mediated expression screening. Int. J. Hematol. 67, 351-359 (1998).

34. T. Shiraishi et al., Increased cytotoxicity of soluble Fas ligand by fusing isoleucine zipper motif. Biochem. Biophys. Res. Commun. 322, 197-202 (2004).

doi:10.1016/j.bbrc.2004.07.098

35. J. Carette et al., Haploid genetic screens in human cells identify host factors used by pathogens. Science 326, 1231-1235 (2009). doi: 10.1126/science.1178955

36. M. A. Nesbit et al., X-linked hypoparathyroidism region on Xq27 is evolutionarily conserved with regions on 3q26 and 13q34 and contains a novel P-type ATPase. Genomics 84, 1060-1070 (2004). doi:10.1016/j.ygeno.2004.08.003

37. R. Higuchi, in PCR protocols: A guide to methods and applications. (Academic Press, San Diego, 1990), pp. 177-188.

38. R. Fukunaga, E. Ishizaka-Ikeda, S. Nagata, Purification and characterization of the receptor for murine granulocyte colony-stimulating factor. J. Biol. Chem. 265, 14008- 
14015 (1990).

39. M. Miksa et al., A novel method to determine the engulfment of apoptotic cells by macrophages using pHrodo succinimidyl ester. J. Immunol. Methods 342, $71-77$ (2009). doi:10.1016/j.jim.2008.11.019

40. S. Toda, R. Hanayama, S. Nagata, Two-step engulfment of apoptotic cells. Mol. Cell. Biol. 32, 118-125 (2012). doi:10.1128/MCB.05993-11

41. C. Toyoshima, G. Inesi, Structural basis of ion pumping by Ca2+-ATPase of the sarcoplasmic reticulum. Anпu Rev Biochem 73, 269-292 (2004). doi:10.1146/annurev.biochem.73.011303.073700

Acknowledgments: We thank Brent H. Cochran for KBM7 cells, K. Higasa and M. Shimizu for help in next-generation sequencing, K. Okamoto-Furuta and H. Kohda for support in electron microscope analysis, and M. Fujii for secretarial assistance. This work was supported in part by Grants-in-Aid from the Ministry of Education, Science, Sports, and Culture in Japan. 
Fig. 1. Screening for phospholipid flippase. (A) KBM7 cells were incubated with $1.5 \mu \mathrm{M}$ NBDphospholipids, treated with bovine serum albumin (BSA), and analyzed by Fluorescence activated cell sorting (FACS). Mean fluorescence intensity (MFI) plotted. (B) Mutagenized KBM7 cells that incorporated low levels $(\sim 1 \%)$ of NBD-PS were collected, and sorted to generate low flipping (LF) cells. (C) Identification of gene-trap insertions. Proximity index plotted for human chromosome with number $(\mathrm{N})$ of insertions. Arrows, insertion positions for sense (red) and antisense-orientation (green). (D) Incorporation of NBD-phospholipids into KBM7, ATP11C $\mathrm{CT}^{\mathrm{GT}}, \mathrm{ATP} 11 \mathrm{C}^{\mathrm{GT}}-\mathrm{h} A T P 11 C, \mathrm{CDC}_{00} \mathrm{~A}^{\mathrm{GT}}$, or CDC50A ${ }^{\mathrm{GT}}-\mathrm{h} C D C 50 A$ cells, expressed as ratio of that with KBM7 cells $(n=3)$. (E) Effect of vanadate on the NBD-PS incorporation into $\mathrm{KBM} 7, \mathrm{ATP} 11 \mathrm{C}^{\mathrm{GT}}$, and $\mathrm{CDC} 0 \mathrm{~A}^{\mathrm{GT}}$ cells, expressed as ratio of that with KBM7 cells in the absence of vanadate $(n=3)$. (F) Annexin V-staining profile of KBM7, ATP11C ${ }^{\mathrm{GT}}, \mathrm{CDC} \mathrm{A}^{\mathrm{GT}}$, and $\mathrm{CDC} 50 \mathrm{~A}^{\mathrm{GT}}$-hCDC50A cells with percentage of Annexin $\mathrm{V}$-positive cells.

Fig. 2. Cleavage of ATP11C during apoptosis. (A) Incorporation of NBD-PS into W3, $\mathrm{ATP} 11 \mathrm{C}^{\mathrm{ED} 22}, \mathrm{ATP} 11 \mathrm{C}^{\mathrm{ED} 23}, \mathrm{ATP} 11 \mathrm{C}^{\mathrm{ED} 22}-\mathrm{h} A T P 11 C$, and ATP11C $\mathrm{CD}^{\mathrm{ED}}-\mathrm{h} A T P 11 C$ cells, expressed as ratio of that with $\mathrm{W} 3$ cells $(\mathrm{n}=3)$. $(\mathrm{B}) \mathrm{W} 3$ and $\mathrm{ATP} 11 \mathrm{C}^{\mathrm{ED} 22}$ cells were incubated for $1 \mathrm{~h}$ with FasL in the presence or absence of $20 \mu \mathrm{M}$ QVD-OPh. Membrane fractions were analyzed by immunoblotting with anti-mATP11C or anti-Fas antibodies (Abs). Middle panel, longer exposure. (C) ATP11C ED22 , ATP11C $\mathrm{ED}^{\mathrm{ED}}$-hATP11C-GFP, or ATP11C $\mathrm{ED}^{\mathrm{E} 22}$-mutant hATP11CGFP cells were incubated for 45 min with FasL, and analyzed by immunoblotting with anti-GFP Abs. (D) W3, ATP11C ${ }^{\mathrm{ED} 22}$, ATP11C ${ }^{\mathrm{ED} 22}-\mathrm{h} A T P 11 C$, and ATP11C ${ }^{\mathrm{ED} 22}-$ Cas $R$ cells were incubated with NBD-PS, treated with BSA, and analyzed by FACS. MFI plotted (n=3). (E) Annexin V- 
staining profile of $\mathrm{W} 3, \mathrm{ATP} 11 \mathrm{C}^{\mathrm{ED} 22}, \mathrm{ATP} 11 \mathrm{C}^{\mathrm{ED} 22}-\mathrm{h} A T P 11 C$, and $\mathrm{ATP} 11 \mathrm{C}^{\mathrm{ED} 22}-$ CasR cells, that were untreated (red) or FasL-treated for $2 \mathrm{~h}$ (blue). On right, immunoblotting of the cell lysates with anti-cleaved caspase 3. (F) W3, ATP11C $\mathrm{ED}^{\mathrm{E} 22}$, ATP11C $\mathrm{ED}^{\mathrm{ED}}-\mathrm{h} A T P 11 C$, and ATP11C ${ }^{\mathrm{ED} 22}$ Cas $R$ cells were treated for 1 or $2 \mathrm{~h}$ with FasL, incubated with $0.5 \mu \mathrm{M}$ NBD-PC for $4 \mathrm{~min}$, and analyzed by FACS. MFI plotted (n=3). (G) W3-Ildm, W3Ildm-hATP11C, and W3Ildm-CasR cells were treated with FasL, labeled with pHrodo, incubated for $1 \mathrm{~h}$ with thio-pMacs, and analyzed by FACS.

Fig. 3. PtdSer exposure in $C D C 50 A^{-/-}$cells. (A) Observation of hATP11C-GFP expressed in $\mathrm{CDC}_{0} \mathrm{~A}^{\mathrm{ED} 29}$ or CDC50A ${ }^{\mathrm{ED} 29}-\mathrm{hCDC50A}$ cells by confocal fluorescence microscopy. DIC, differential interference contrast. Scale bar, $5 \mu \mathrm{m}$. (B) Incorporation of NBD-PS into W3-Ildm, $\mathrm{CDC}_{00} \mathrm{~A}^{\mathrm{ED} 29}, \mathrm{CDC}_{00} \mathrm{~A}^{\mathrm{ED} 62}, \mathrm{CDC} \mathrm{A}^{\mathrm{ED} 29}-\mathrm{h} C D C 50 A, \mathrm{CDC}^{2} \mathrm{~A}^{\mathrm{ED} 62}-\mathrm{h} C D C 50 A$, and W3D430G-L cells, expressed as ratio of that with W3-Ildm cells (n=3). (C) W3-Ildm, CDC50A ${ }^{\text {ED29, }}$ CDC50A ${ }^{\mathrm{ED} 62}$ cells, and their hCDC50A-transformants (red) were stained with Cy5-Annexin V or FITC-MFG-E8 in Annexin V-buffer. (D) W3-Ildm, CDC50A ${ }^{\text {ED29 }}$, and W3-D430G-L cells were incubated at room temperature for 5 min with FITC-MFG-E8 in HEPES buffered saline or in IMDM-10\% FCS. MFI is indicated (n=3). In lower panels, W3-Ildm, CDC50A ${ }^{\text {ED29 }}$, and CDC50A ${ }^{\text {ED62 }}$ cells were stained with FITC-MFG-E8 in IMDM-10\% FCS, and observed by confocal fluorescence microscopy. Scale bar, $10 \mu \mathrm{m}$.

Fig. 4. Engulfment of viable cells. (A) Thio-pMacs were incubated for $2 \mathrm{~h}$ with pHrodo-labeled W3-Ildm, CDC50A ${ }^{\mathrm{ED} 29}, \mathrm{CDC} \mathrm{A}^{\mathrm{ED} 29}$-hCDC50A, or W3-D430G-L cells in the presence or absence of $4 \mu \mathrm{g} / \mathrm{ml}$ of D89E, and analyzed by FACS. (B) Wild-type or MerTK ${ }^{-/}$thio-pMacs were incubated for $2 \mathrm{~h}$ with pHrodo-CDC50A ${ }^{\mathrm{ED} 29}$ and analyzed by FACS. (C) pHrodo- 
CDC50A ${ }^{\mathrm{ED} 29}$ was incubated with thio-pMacs in the presence of CellEvent ${ }^{\mathrm{TM}}$. Images for pHrodo (red), CellEvent (green), and DIC, captured every $1.5 \mathrm{~min}$. Scale bar, $10 \mu \mathrm{m}$. Engulfment of CellEvent-negative (living) and -positive (dead) cells was followed for at least 130 events in 30 fields of 3 independent experiments. The percentages of dead or living cell engulfment are at right. (D) Releases of engulfed CDC50A ${ }^{\mathrm{ED} 29}$ (arrowhead) from thio-pMacs. Scale bar, $10 \mu \mathrm{m}$. (E) Electron transmission micrograph of thio-pMacs engulfing CDC50A ${ }^{\mathrm{ED} 29}$ or FasL-treated W3-Ildm cells. Scale bar, $2 \mu \mathrm{m}$. N, macrophage nucleus. L, engulfed living cells. A, engulfed apoptotic cells. (F) W3-Ildm, CDC50A ${ }^{\mathrm{ED} 29}$, and $\mathrm{CDC} 50 \mathrm{~A}^{\mathrm{ED} 29}-\mathrm{h} C D C 50 A\left(1 \times 10^{6}\right.$ cells $)$ were transplanted subcutaneously into nude mice $(\mathrm{N}=6-11)$, and tumors weighed four weeks later. 
ANme A Self-archived copy in

KYOTO UNIVERSITY
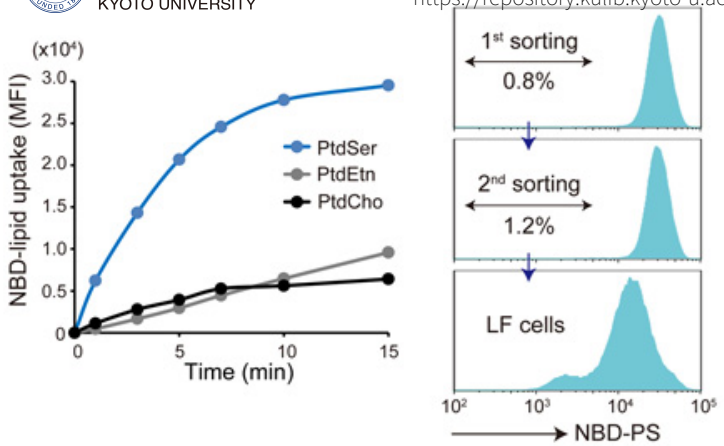

A 2 京都大学

Cository

然

즘 0.05 CDC50A

$$
\mathrm{N}=41
$$
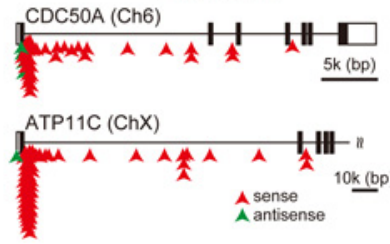

D
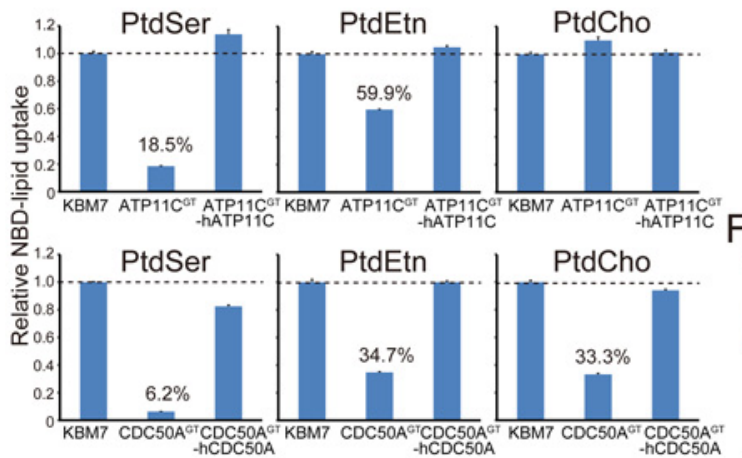

E

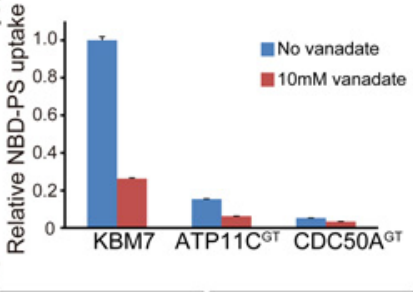

Segawa et al. Figure 1 


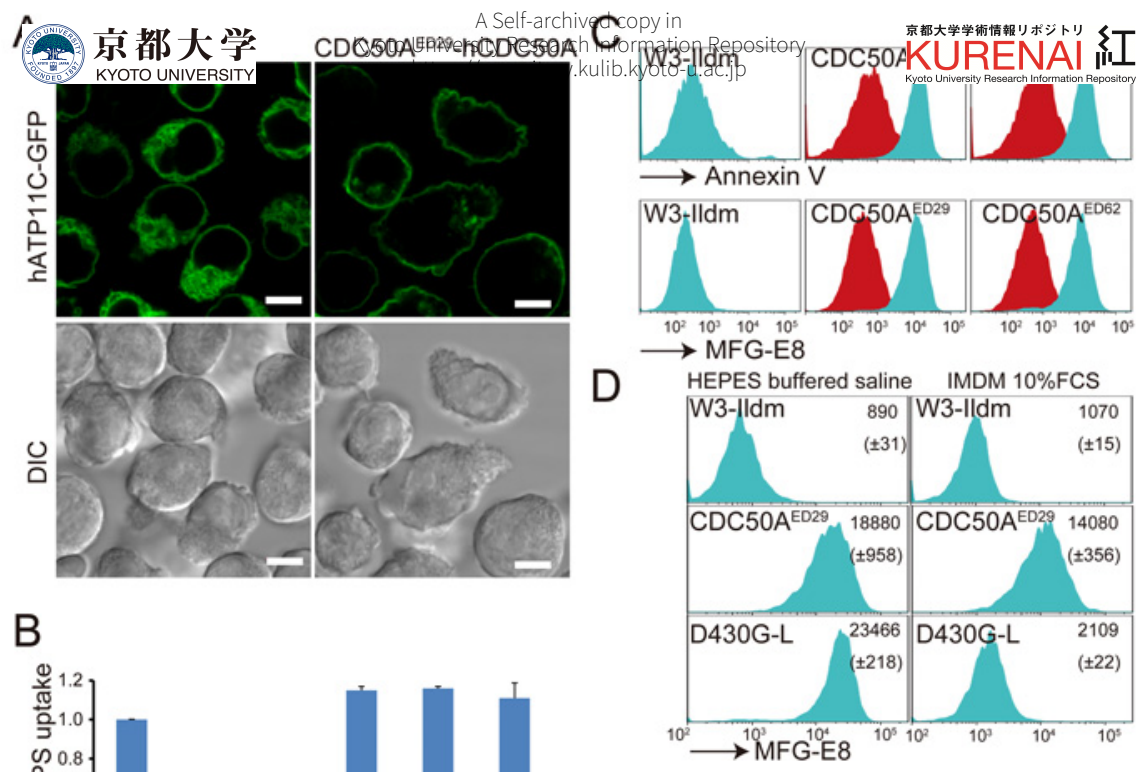

这

0.6 .

0.4

$\sum_{0.2}$

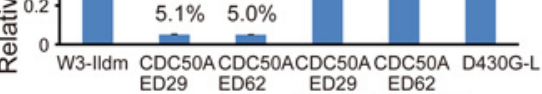
-hCDC50A-hCDC50A

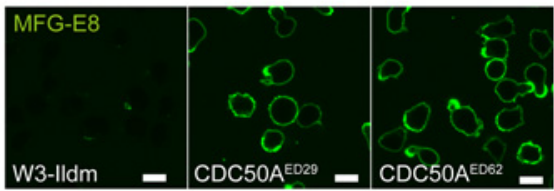

Segawa et al. Figure 3 


\section{Supplementary Materials for \\ Caspase-Mediated Cleavage of Phospholipid Flippase for Apoptotic Phosphatidylserine Exposure}

Katsumori Segawa, Sachiko Kurata, Yuichi Yanagihashi, Thijn R. Brummelkamp, Fumihiko Matsuda, and Shigekazu Nagata*

correspondence to: snagata@mfour.med.kyoto-u.ac.jp 
Materials and Methods

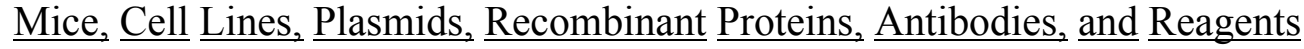

C57BL/6J and BALB/c nude mice were purchased from Japan Clea. MerTK ${ }^{-/-}$mice (31) were from the Jackson Laboratory. All mouse studies were approved by the Ethics Review Committee for Animal Experimentation of the Graduate School of Medicine, Kyoto University.

Human KBM7 cell line (11) was provided by Dr. Brent H. Cochran (Tufts University School of Medicine) and maintained in Iscove's Modified Dulbecco's Medium (IMDM) containing 10\% fetal calf serum (FCS). W3 cells are transformants of mouse T-cell lymphoma cells (WR19L) that express mouse (m)Fas (32), and W3-Ildm cells are WR19L cells expressing $\mathrm{mFas}$ and a caspase-resistant form of the inhibitor of caspase-activated DNase (ICAD)(17). W3 cells, W3-Ildm cells and human Jurkat cells were cultured in RPMI1640 containing 10\% FCS. W3-Ildm transformants expressing a constitutively active form of mTMEM16F (W3-D430G-L) were described previously (18). HEK293T cells were cultured in DMEM containing 10\% FCS. For the analysis of phosphatidylserine (PtdSer) exposure, FCS was centrifuged at $100,000 \times g$ overnight at $4^{\circ} \mathrm{C}$, followed by filtration using $0.22-\mu \mathrm{m}$ membranes (Millipore) to remove microvesicles or debris.

The gene-trap constructs (pGT-GFP, pGT-GFP+1, and pGT-GFP+2) were described previously (12). The retrovirus vector pMXs-puro (33) and packaging plasmid pGag-pol-IRESbsr were from Dr. Toshio Kitamura (Institute of Medical Science, University of Tokyo). The plasmid pCMV-VSV-G was provided by Dr. Hiroyuki Miyoshi (Riken Bioresource Center, Riken). pAdVAntage ${ }^{\mathrm{TM}}$, pX260, and pX330 (10) were purchased from Life Technologies (Invitrogen) and Addgene, respectively. Recombinant leucine-zippered human FasL (FasL) (34) and the D89E mutant of mMFG-E8 (19) were produced in COS7 and HEK293T cells, respectively, and purified. The Cy5-labeled Annexin V and fluorescein isothiocyanate (FITC)labeled bovine MFG-E8 (BLAC-FITC) were purchased from Biovision, and Hematologic Technologies, respectively. pHrodo succinimidyl ester (pHrodo) and CellEvent ${ }^{\mathrm{TM}}$ Caspase-3/7 Green were purchased from Life Technologies. 1-oleoyl-2-\{6-[(7-nitro-2-1,3-benzoxadiazol-4yl)amino]hexanoyl $\}$-sn-glycero-3-phosphoserine (NBD-PS), 1-oleoyl-2-\{6-[(7-nitro-2-1,3benzoxadiazol-4-yl)amino]hexanoyl $\}$-sn-glycero-3-phosphoethanolamine (NBD-PE), and 1oleoyl-2-\{6-[(7-nitro-2-1,3-benzoxadiazol-4-yl)amino]hexanoyl $\}$-sn-glycero-3-phosphocholine (NBD-PC) were purchased from Avanti Polar Lipids.

Rabbit antibodies $(\mathrm{Ab})$ against $\mathrm{mATP} 11 \mathrm{C}$ were custom-prepared at the Protein Purity Co. In brief, a peptide, PYNDEPWYNQKTQKERET (amino acids 317-334) with an extra cysteine residue at the $\mathrm{N}$-terminus, was conjugated to keyhole limpet hemocyanin with $m$ maleimidobenzoyl-N-hydroxysuccinimide ester (Pierce), and used to immunize rabbits. The antibodies were affinity-purified from the serum using AF amino-Toyopearl beads (AF-Amino650, Tosoh Co) bound to the peptide. Rat anti-mouse Fas mAb (clone OB-22) was prepared by the standard protocol in our laboratory. Rabbit monoclonal antibodies (mAb) against activated caspase 3 (Clone 5A1E) and mouse anti- $\alpha$-tubulin mAb (Clone DM1A) were from Cell Signaling and Calbiochem, respectively. Allophycocyanin (APC)-conjugated rat mAb against mouse Mac-1 (clone M1/70), and mouse anti-Green fluorescent protein (GFP) mAb (Clone JL8) were from BioLegend and Clontech, respectively. Horseradish peroxidase (HRP)-conjugated goat anti-mouse immunoglobulins (Igs), goat anti-rabbit Igs or rabbit anti-rat Igs were obtained from Dako. 


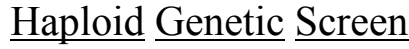

The haploid genetic screen was performed essentially as described $(12,35)$. In brief, to produce the gene trap virus, HEK293T cells $\left(2.4 \times 10^{7}\right.$ cells $)$ were co-transfected using Fugene6 (Promega) with a mixture $(36 \mu \mathrm{g})$ of pGT-GFP, pGT-GFP +1 , and pGT-GFP +2 , combined with $8.4 \mu \mathrm{g}$ pAdvantage, $9.0 \mu \mathrm{g}$ pCMV-VSV-G, and $9.6 \mu \mathrm{g}$ pGag-pol-IRES-bsr, and incubated for 48 $\mathrm{h}$. The virus in the supernatant was concentrated by centrifugation at $6,000 \times g$ for $16 \mathrm{~h}$. KBM7 cells $\left(1 \times 10^{8}\right)$ were seeded at $1.5 \times 10^{6}$ cells per well in 24 -well culture dishes (Corning), and infected with the concentrated virus using spin-infection at $700 \times g$ for $45 \mathrm{~min}$ in the presence of 8 $\mu \mathrm{g} / \mathrm{ml}$ polybrene. The infected cells were expanded for 4 days and used for screening.

The cells that lost the ability to transport aminophospholipids across the plasma membrane were enriched by repeating the FACS sorting twice. In brief, $6 \times 10^{7}$ mutagenized KBM7 cells were washed with PBS, and incubated at room temperature for $40 \mathrm{~min}$ with $1.5 \mu \mathrm{M}$ NBD-PS in Hank's balanced salt solution (HBSS) containing $2 \mathrm{mM} \mathrm{CaCl} 2$ and $1 \mathrm{mM} \mathrm{MgCl}$. The cells were collected by centrifugation, and suspended in HBSS containing $5 \mathrm{mg} / \mathrm{ml}$ fatty-acid-free bovine serum albumin (BSA) (Sigma-Aldrich) to remove NBD-PS on the cell surface. The cells were subjected to flow cytometry at $4^{\circ} \mathrm{C}$ using the FACSAria II system (BD Biosciences), and approximately $1 \%$ of the cells, which exhibited less efficient NBD-PS incorporation, were collected. The sorted cells were grown for 1-2 weeks in IMDM containing 10\% FCS, and subjected to a second sorting as described above. The resultant cells exhibiting defective NBDPS incorporation were designated as Low-Flipping or LF cells.

\section{Mapping of Gene-Trap $\underline{\text { Insertion Sites }}$}

Host sequences flanking the proviral insertion were identified by inverse polymerase chain reaction (PCR), followed by deep sequencing as described $(12,35)$. In brief, genomic DNA was isolated from $2 \times 10^{6} \mathrm{LF}$ cells using the QIAamp DNA Mini Kit (Qiagen), and $4 \mu \mathrm{g}$ DNA was digested with NlaIII. The digested DNA was purified using the Wizard SV Gel and PCR cleanup column (Promega), and $1.0 \mu \mathrm{g}$ DNA was ligated with T4 DNA ligase (Takara Bio) in a volume of $300 \mu \mathrm{l}$. The DNA was purified as above, and subjected to PCR using outward-facing primers complementary to the internal sequence in the gene trap vector (5'AATGATACGGCGACCACCGAGATCTACACATCTGATGGTTCTCTAGCTTGCC-3' and 5'-CAAGCAGAAGACGGCATACGAGATACCCAGGTTAAGATCAAGGTC-3'; adapter sequences for deep sequencing are underlined). The PCR products were purified by the Wizard SV Gel and PCR clean-up column, and sequenced with a primer (5'-

CTAGCTTGCCAAACCTACAGGTGGGGTCTTTCA-3') on a MiSeq sequencer (Illumina).

The 45-bp sequences in the FASTQ data file were mapped to the human genome (UCSC human genome 19; hg19) using Burrows-Wheeler Aligner software. The criteria used by Carette et al. (12) were applied to identify unique insertion sites. That is, the sequences carrying mismatches in the 45-bp sequence were removed, and if several insertions aligned 1 or 2 base pairs apart, only 1 was retained. The proximity index for a given insertion was defined as the inverse value that was calculated from the average distance between the given insertion and the two neighboring upstream and downstream insertions. The pipeline for the mass sequence 
analysis was prepared as a custom-order at Amelieff Co. Forty-one insertions were found in $C D C 50 A$ (Cell division cycle protein 50A or TMEM30A), and 86 insertions in ATP11C.

$\underline{\text { Isolation of }} \underline{\mathrm{KBM} 7} \underline{\text { Clones }} \underline{\text { Carrying the Gene-Trap }} \underline{\text { Mutations }}$

To obtain clonal cell lines that carried gene-trap insertions, the LF cells were subjected to limiting dilution. Genomic DNA was isolated from each clone using the QIAamp DNA Mini Kit, digested with NlaIII, and purified using the Wizard SV Gel and PCR clean-up column. The DNA was ligated with T4 DNA ligase, purified as above, and subjected to PCR using outward-facing primers complementary to the internal sequence in the gene trap vector $\left(5^{\prime}\right.$ -

CTGCAGCATCGTTCTGTGTT-3' and 5'- TCTCCAAATCTCGGTGGAAC-3'). The amplified PCR products were directly sequenced using a DNA sequencer (ABI PRISM 3100 Genetic Analyzer, Life Technologies) with the primer (5'-CTCGGTGGAACCTCCAAAT-3'). Clones carrying mutations in $A T P 11 C$ or $C D C 50 A$ were designated ATP $11 C^{\mathrm{GT}}$ and $C D C 50 A^{\mathrm{GT}}$, respectively.

\section{Gene Editing}

The CRISPR (Clustered Regularly Interspaced Short Palindromic Repeats)-Cas (CRISPRassociated) system (16) was used to edit the mCDC50A and ATP11C genes in W3 and W3-Ildm cells. Suitable target sequences in the mCDC50A (TMEM30A) (ID: MGI 106402) and mATP11C (ID: MGI 1859661) genes were designed using the CRISPR Design Tool at Zhang's Laboratory at UCSC (http://www.genome-engineering.org/crispr/?page_id=41). Complementary oligonucleotides (5'-AAACCATCGGCCTCATCTTCATCCCCATCGGCATGT-3' and 5' TAAAACATGCCGATGGGGATGAAGATGAGGCCGATG-3'for CDC50A, and 5'CACCGTCACCAAACGGTTGAGGGTC-3' and 5'-AAACGACCCTCAACCGTTTGGTGAC3 ' for $A T P 11 C$, with target sequences for CDC50A and $A T P 11 C$ underlined) were phosphorylated with $\mathrm{T} 4$ polynucleotide kinase (Takara Bio), heated at $95^{\circ} \mathrm{C}$ for $5 \mathrm{~min}$, left at room temperature for annealing, ligated into $B b s \mathrm{I}$-digested pX260 (for CDC50A) or pX330 (for $A T P 11 C$ ) vectors, and used to transform $E$. coli. The $\mathrm{pX}$ plasmid DNA carrying the targeted sequences was introduced into W3 or W3-Ildm cells by electroporation using a Super Electroporator NEPA21 type II (NepaGene). After culturing for 3 days in RPMI containing 10\% $\mathrm{FCS}$, the cells were transfected again with the $\mathrm{pX}$ vectors.

To identify clones carrying mutations, the cells were subjected to limiting dilution 3 days after the second transfection, and the genomic DNA was prepared from individual clones using a QIAamp DNA Mini Kit. The DNA fragment flanking the CRISPR-target site was amplified by PCR using primers (CDC50A: 5'-CGTCTCCTAAAGACGCCCG-3' and 5'TCCACCCGACATTCTAGCTG-3', and ATP11C: 5'- GCAGTGTGTTTTGTGGACGG-3' and 5'- CCGGGTTTCCGCTAAAACGC-3'), and directly sequenced using a DNA sequencer (ABI PRISM 3100 Genetic Analyzer). Gene editing at the CDC50A gene locus was observed in 6 of 96 clones, and 2 of them $\left(\mathrm{CDC}_{00 \mathrm{~A}^{\mathrm{ED} 29}}\right.$ and $\mathrm{CDC} \mathrm{AA}^{\mathrm{ED} 62}$ ) carried biallelic changes that resulted in frame-shifting indels. Gene editing at the $A T P 11 C$ gene locus was observed in 9 of 34 clones, 4 of which were $A T P 11 C$-deficient clones carrying biallelic indels. Among them, 2 clones $\left(\mathrm{ATP} 11 \mathrm{C}^{\mathrm{ED} 22}\right.$ and ATP11C ${ }^{\mathrm{ED} 23}$ ) were used in this study.

\section{5'-RACE-PCR}


Rapid amplification of 5'-cDNA ends (RACE) was performed using a kit (5'-Full RACE Core Set; Takara Bio) according to the manufacturer's instructions. In brief, total RNA was prepared from KBM7 cells with the RNeasy Mini Kit (Qiagen). The first-strand cDNA was synthesized using AMV (Avian Myeloblastosis Virus) Reverse Transcriptase with a 5'phosphorylated primer (5'-CTTAGATGAGAC-3'). After degrading RNA with RNase H, the synthesized first-strand cDNA was ligated with T4 RNA ligase, and used as a template for nested PCR. Nested PCR was carried out using primers as follows (for $1^{\text {st }}$ PCR; 5' -

TGGCAATCATCCAGTTTCGG-3' and 5'-ACACTGTGCGTGTGCCAAC-3', for 2 ${ }^{\text {nd }} P C R$; 5'CGGAAACAGAAGCTTACATTGC-3' and 5'-TCGTTTCTCTTCTCCAGCAC-3'). The PCR product was cloned in the pGEM-T easy vector, and DNA sequences were determined with a DNA sequencer (ABI PRISM 3100 Genetic Analyzer).

Transformation of Human and Mouse Cell Lines

The human CDC50A cDNA (NCBI: NM_018247.3) was prepared by RT-PCR with RNA from KBM7 cells. Since the native hATP11C cDNA (NCBI:XM_005262405.1) (36) produced low protein levels in mammalian cells, a sequence with enhanced mRNA stability and translational efficiency was custom ordered from GENEART (Regensburg, Germany). To generate the Mut $1+2,1+3,2+3$, or $1+2+3$ mutants, $\mathrm{h} A T P 11 C$ cDNA was mutated by recombinant PCR (37) using the following primers carrying the mutated nucleotides, with the sequence for the restriction enzyme site underlined. hATP11C (5'CATTTAATTAAGCCACCATGTTCAG-3' and 5'-CCAGGAATTCCAGCACGTTGGACTC3'). Mut1, 5'-CTGTCTGGCTCAGGCCGGCCACTTCCTGGGTCACG-3' and 5'CGTGACCCAGGAAGTGGCCGGCCTGAGCCAGACAG-3'; Mut2, 5’GAAGTAGGTCAGTGTGCCAGCTGTCTGGCTCAGGC-3' and 5'GCCTGAGCCAGACAGCTGGCACACTGACCTACTTC-3'; Mut3, 5'CTCTGTGGCGCCGGCCACGGCGGCGTTGGTCTTGA-3' and 5'TCAAGACCAACGCCGCCGTGGCCGGCGCCACAGAG-3'. The authenticity of the cDNAs was confirmed by DNA sequencing.

KBM7 cells, W3 cells, W3-Ildm cells, Jurkat cells, and their derivatives were transformed using a retrovirus vector carrying the Vesicular stomatitis virus (VSV)-G envelope gene. The cDNAs were Flag- or GFP-tagged at the C-terminus, inserted into the pMXs-puro vector, and introduced into HEK293T cells using Fugene 6 (Promega), together with pGag-pol-IRES-bsr, pCMV-VSV-G, and pAdVAntage ${ }^{\mathrm{TM}}$. The produced retrovirus was concentrated by centrifugation and used to infect KBM7 cells, W3 cells, W3-Ildm cells, or Jurkat cells. The infected cells were cultured in the presence of puromycin at $0.8 \mu \mathrm{g} / \mathrm{ml}$ (for KBM7 cells) or 1 $\mu \mathrm{g} / \mathrm{ml}$ (for W3 cells, W3-Ildm cells or Jurkat cells).

To examine cellular localization of ATP11C, CDC50A ${ }^{\mathrm{ED} 29}$ or $\mathrm{CDC} 0 \mathrm{~A}^{\mathrm{ED} 29}$ transformants expressing hCDC50A were infected by retrovirus prepared with pMXs-puro hATP11C-GFP, and stable transformants were selected in medium containing $1.0 \mu \mathrm{g} / \mathrm{ml}$ puromycin. For microscopic observation, the cells were grown on glass-bottom dishes (Iwaki) and observed in phenol redfree DMEM containing 10\% FCS by confocal microscopy (FV1000-D; Olympus).

$\underline{\text { Induction of Apoptosis and Detection of Phosphatidylserine }}$ 
To induce apoptosis, $1 \times 10^{6} \mathrm{~W} 3$-Ildm cells were treated with 33 units $/ \mathrm{ml} \mathrm{FasL}$ at $37^{\circ} \mathrm{C}$ for 1-2 $\mathrm{h}$, and the cell viability was determined by the WST-1 assay with 2-(4-Iodophenyl)-3-(4nitrophenyl)-5-(2,4-disulfophenyl)-2H-tetrazolium, monosodium salt (WST-1; Dojin Laboratories) and 1-Methoxy-5-methylphenazinium methylsulfate, as described (18).

To detect PtdSer on the cell surface, cells were incubated at $25^{\circ} \mathrm{C}$ for 5 min with $1-2,000$ fold diluted Cy5-Annexin V or 800 ng/ml FITC-MFG-E8 in Annexin V- buffer (10 mM Hepes$\mathrm{KOH}(\mathrm{pH} 7.4), 140 \mathrm{mM} \mathrm{NaCl}$, and $2.5 \mathrm{mM} \mathrm{CaCl}_{2}$ ) or IMDM supplemented with $10 \% \mathrm{FCS}$, followed by incubation with $200 \mathrm{nM} \mathrm{SYTOX}^{\mathbb{B}}$ Blue (Life Technologies Molecular Probes), and analyzed by a FACSAria II or FACSCanto II. For microscopic observation, $2 \times 10^{5}$ cells on 8 well Lab-Tek II chamber slides (Nalge Nunc) were incubated on ice for $15 \mathrm{~min}$ with $4 \mu \mathrm{g} / \mathrm{ml}$ FITC-conjugated MFG-E8 in staining buffer and observed by confocal fluorescence microscopy (FV1000-D).

\section{$\underline{\text { Caspase Treatment }}$}

The membrane fractions were prepared from cells expressing hATP11C-GFP or its mutants as described (38), and lysed in $20 \mathrm{mM}$ Tris- $\mathrm{HCl}$ (pH 7.4), $140 \mathrm{mM} \mathrm{NaCl}, 1 \%$ Triton X-100, 10\% glycerol, and $1 \mathrm{mM}$ ( $p$-aminophenyl) methanesulfonyl fluoride (APMSF). After removing insoluble materials by centrifugation, the membrane proteins $(10 \mu \mathrm{g})$ were incubated at $37^{\circ} \mathrm{C}$ for $1 \mathrm{~h}$ with 3 units of various recombinant human caspases (Biovision) in $100 \mu \mathrm{l}$ of $50 \mathrm{mM}$ Hepes$\mathrm{NaOH}$ (pH 7.4), 5\% glycerol, 5 mM DTT, 10 mM EDTA, $0.1 \mathrm{mM}$ APMSF and 0.1\% CHAPS, and analyzed by Western blotting.

\section{$\underline{\text { Immunoblotting }}$}

Cells or membrane fractions were lysed in $50 \mathrm{mM}$ HEPES-NaOH (pH 8.0) buffer containing $1 \% \mathrm{NP}-40,0.1 \% \mathrm{SDS}, 0.5 \%$ sodium deoxycholate, $150 \mathrm{mM} \mathrm{NaCl}$, and a cocktail of protease inhibitors [cOmplete, Mini, EDTA-free, Roche Diagnostics]). After removing insoluble materials by centrifugation, the lysates were mixed 3:1 with $3 \times$ SDS sample buffer $(200 \mathrm{mM}$ Tris-HCl [pH 6.8], 10\% SDS, 25\% glycerol, 15\% $\beta$-mercaptoethanol, and $0.05 \%$ bromophenol blue), and incubated at room temperature for $20 \mathrm{~min}$. Proteins were separated by polyacrylamide gel electrophoresis (PAGE) in the presence of $0.1 \%$ SDS using a $7.5 \%$ or $10-20 \%$ gradient gel (Bio Craft), and transferred to a Polyvinylidene difluoride (PVDF) membrane (Millipore). The membranes were probed with mouse anti-GFP mAb, rabbit anti-active caspase- $3 \mathrm{mAb}$, rabbit anti-hATP11C Ab, rabbit anti- $\alpha$-tubulin $\mathrm{mAb}$, or rat anti-mFas $\mathrm{mAb}$, followed by incubation with HRP-conjugated goat anti-mouse Igs, goat anti-rabbit Igs or rabbit anti-rat Igs. The peroxidase activity was detected by the Western Lightning-ECL system (PerkinElmer).

\section{In vitro Phagocytosis Assay}

To prepare thioglycollate-elicited peritoneal macrophages (thio-pMacs), female C57BL/6J mice at 7-12 weeks of age were injected intraperitoneally with $60 \mathrm{mg}$ of thioglycollate (SigmaAldrich), and peritoneal macrophages were collected 4 days later. Phagocytosis was assayed by following the transport of pHrodo-stained prey into macrophage lysosomes $(39,40)$. In brief, $5 \times 10^{5}$ thio-pMacs were grown overnight in 12-well plates (Corning). Growing or apoptotic cells $\left(2.0 \times 10^{7}\right)$ were washed with PBS and incubated with $40 \mathrm{ng} / \mathrm{ml}$ pHrodo for $10 \mathrm{~min}$ at room 
temperature. After stopping the reaction with $2 \mathrm{ml} \mathrm{FCS}$, the cells were washed with IMDM containing $10 \%$ FCS, added to the macrophages in the medium containing $1 \%$ methyl cellulose (Sigma-Aldrich), spun at $500 \times g$ for 4 min at room temperature using a swinging rotor, and incubated at $37^{\circ} \mathrm{C}$. The macrophages were detached from the plate by treatment with $0.25 \%$ trypsin, stained with APC-conjugated rat anti-mouse Mac1, suspended in $20 \mathrm{mM} \mathrm{CHES-NaOH}$ buffer ( $\mathrm{pH}$ 9.0) containing $150 \mathrm{mM} \mathrm{NaCl}, 2 \% \mathrm{FCS}$, and $200 \mathrm{nM}$ Sytox blue, and analyzed by flow cytometry using the FACSCanto II. Phagocytosis was defined as the percentage of pHrodopositive cells in the Mac- $1^{+}$Sytox blue ${ }^{-}$population.

For time-lapse observation, thio-pMacs $\left(5 \times 10^{4}\right)$ were grown overnight in eight-well LabTek II chambers coated with fibronectin. The pHrodo-labeled cells $\left(2 \times 10^{5}\right)$ in IMDM containing $10 \%$ FCS, $1 \%$ methylcellulose and $5 \mu \mathrm{M}$ CellEvent ${ }^{\mathrm{TM}}$ Caspase-3/7 Green were added to the macrophages, and the mixture was spun at $500 \times \mathrm{g}$ for $4 \mathrm{~min}$ at room temperature. The cell culture was followed for 3-4 h in real time using a confocal microscope (FV1000-D), and images were captured every 1-2 min.

\section{Electron Microscopy}

Mouse thio-pMacs were incubated for $2 \mathrm{~h}$ with prey in IMDM containing $10 \%$ FCS and 1\% methylcellulose as described above. Macrophages were then detached from the plate by scraping, and fixed by incubation at $4^{\circ} \mathrm{C}$ overnight in PBS containing $4 \%$ paraformaldehyde and $2 \%$ glutaraldehyde (Nacalai Tesque). After washing with $0.1 \mathrm{M}$ phosphate buffer 3 times, the samples were post-fixed with at $4^{\circ} \mathrm{C}$ for $2 \mathrm{~h}$ with $1 \% \mathrm{OsO}_{4}$ in $0.1 \mathrm{M}$ phosphate buffer, and dehydrated by successive incubations in serially diluted ethanol $(50,60,70,80,90$, and 99\% ethanol) for $20 \mathrm{~min}$ each, followed by dipping into $100 \%$ ethanol for $30 \mathrm{~min}$ twice. The samples were successively incubated twice in propylene oxide for $1 \mathrm{~h}$, in a 1:1 mixture of propylene oxide and epoxide (Luveak 812, Nacalai Tesque) for $1.5 \mathrm{~h}$, in a 1:3 mixture of propylene oxide and epoxide for $1.5 \mathrm{~h}$, and in epoxide for $12 \mathrm{~h}$. They were then embedded in epoxide by incubating at $60^{\circ} \mathrm{C}$ for 3 days. Ultrathin sections $(60-80 \mathrm{~nm})$ were cut with an ultramicrotome EM UC6 (Leica), stained with uranyl acetate and lead citrate, and observed with an electron microscope H-7650 (Hitachi).

\section{$\underline{\text { Internalization of NBD Lipids. }}$}

Cells $\left(2 \times 10^{6}\right)$ were incubated with $1.5 \mu \mathrm{M}$ NBD-PS, NBD-PE, or NBD-PC at $25^{\circ} \mathrm{C}$ for 5 min in $600 \mu \mathrm{l}$ of HBSS containing $1 \mathrm{mM} \mathrm{MgCl}_{2}$ and $2.5 \mathrm{mM} \mathrm{CaCl}_{2}$. After incubation, the cells were collected by centrifugation, resuspended in HBSS containing $5 \mathrm{mg} / \mathrm{ml}$ fatty-acid-free BSA, and analyzed by a FACSAria II. To determine the scramblase activity, $1.5 \times 10^{6}$ cells were incubated at $25^{\circ} \mathrm{C}$ for 4 min with $0.5 \mu \mathrm{M}$ NBD-PC.

\section{Tumor Development}

To develop tumor in nude mice, $1 \times 10^{6}$ cells were subcutaneously injected into 7-week-old female BALB/c athymic nude mice. Four weeks later, the tumors were dissected and weighed.

$\underline{\text { Reverse }} \underline{\text { Transcription }}(\underline{\mathrm{RT})-\mathrm{PCR}}$ 
Total RNA was prepared with Isogen (Nippon Gene), followed by the RNeasy Mini Kit (Qiagen), and was reverse-transcribed with a High Capacity RNA-to-cDNA ${ }^{\mathrm{TM}}$ Kit (Life Technologies, Applied Biosystems). The cDNA was amplified using LightCycler 480 SYBR Green I Master (Roche Diagnostics). Primers for real-time RT-PCR were:

hCDC50A, 5'-CGATGGCGATGAACTATAACGC-3' and 5'CGGTATAATCAATCTCGATCTC-3'; hATP11C, 5'-GGAACGTAATGCAATGGATGGG-3' and 5'-GGTTAGTTCTAAGAGCTCAGTG-3'; h $\beta$-actin, 5'-GCATCCTCACCCTGAAGTAC3' and 5'-CTTAATGTCACGCACGATTTC-3';

mCDC50A, 5'-TGCCAACAGCATGTTTAATGA-3' and 5' TTCGAGGCTCTCTTTTCCAG-3'; mCDC50B, 5'-AACGACTCCTTCTCGCTCTG-3' and 5'CACGAAGTCCTGGTTGATGA-3'; mCDC50C, 5'-TTTCGGAATCCAAGATCCAG-3' and 5'-CAGTCGGCGGTACAGTTTTT-3'; mATP8A1, 5'-TGTGTGCTTGAAAGCTGGAC-3' and 5'-CACCCAGAAGACTCCAGAGC-3'; mATP8A2, 5'-ATTGTTCCTGGTTCCGACTG-3' and 5'-GGAGGTGTCTTCCTGCTGAG-3'; mATP8B1, 5'-TGCCGTGTGCTTACTACCTG-3' and 5'-GGAGATGAGGTCTGCGTAGC-3'; mATP8B2, 5'-CAGGCCAGTTGAACCTCCTA-3' and 5'-GCACACTGACCACAATGACC-3'; mATP8B3, 5'-TGTACTCAATGTGGCCCTGA-3' and 5'-GAGAAGGCATAGCTGGAACG-3'; mATP8B4, 5'-CTCCCTGAGCCAGAAGTTTG3' and 5'-GTGATGAGCTCTCCGTAGCC-3'; mATP8B5, 5'-TCCAGTCCTTCTCCCTGCTA3' and 5'-GGCCACACCTAGGAAATTGA-3'; mATP9A, 5'-ACGATGTTTCCCGTGTTCTC3' and 5'-GAAGGAGATTGCCACGATGT-3'; mATP9B, 5'-CGAGTTTGTCCATGTTGTGG3' and 5'-GAAAGCGCCAAAAGACACTC-3'; mATP10A, 5'-

ACCCTTACTGGACCATGCAG-3' and 5'- GCTGTCCCTGAGCAAAAGTC-3'; mATP10B, 5'- GTGATGGAAAGGCAGCTCTC-3' and 5'-AGGCAGAAGCAGAAGCAGAG-3'; mATP10D, 5'-CCGTGTTTCCATCTCCAGTT-3' and 5'- CAGAAGACCCAGGTGTTGGT-3'; mATP11A, 5' - CTGGCGGGTGTTCATTTACT-3' and 5'-TGACAGTGAGCACCATCACA3'; mATP11B,5'-TTTTGGGCTCCCAGAATATG-3' and 5' - TTCTTCCAACAGACGCACAC3'; mATP11C, 5'-TTACAGTTGGGGCCCTTCTT-3' and 5' -TATCCAAGGCGAGCTTCAGA3'; m $\beta$-actin, 5'-TGTGATGGTGGGAATGGGTCAG-3' and 5'TTTGATGTCACGCACGATTTCC-3'.

The RT-PCR analysis for P4-ATPase and CDC50 family members in KBM7 cells was carried out with specific primers described by Takatsu et al (13).

\section{$\underline{\text { Statistical Analysis }}$}

All data were expressed as the mean with S.D. The statistical significance of the differences between groups was determined using Student's $t$-test. 
A

1. Reverse transcription

B

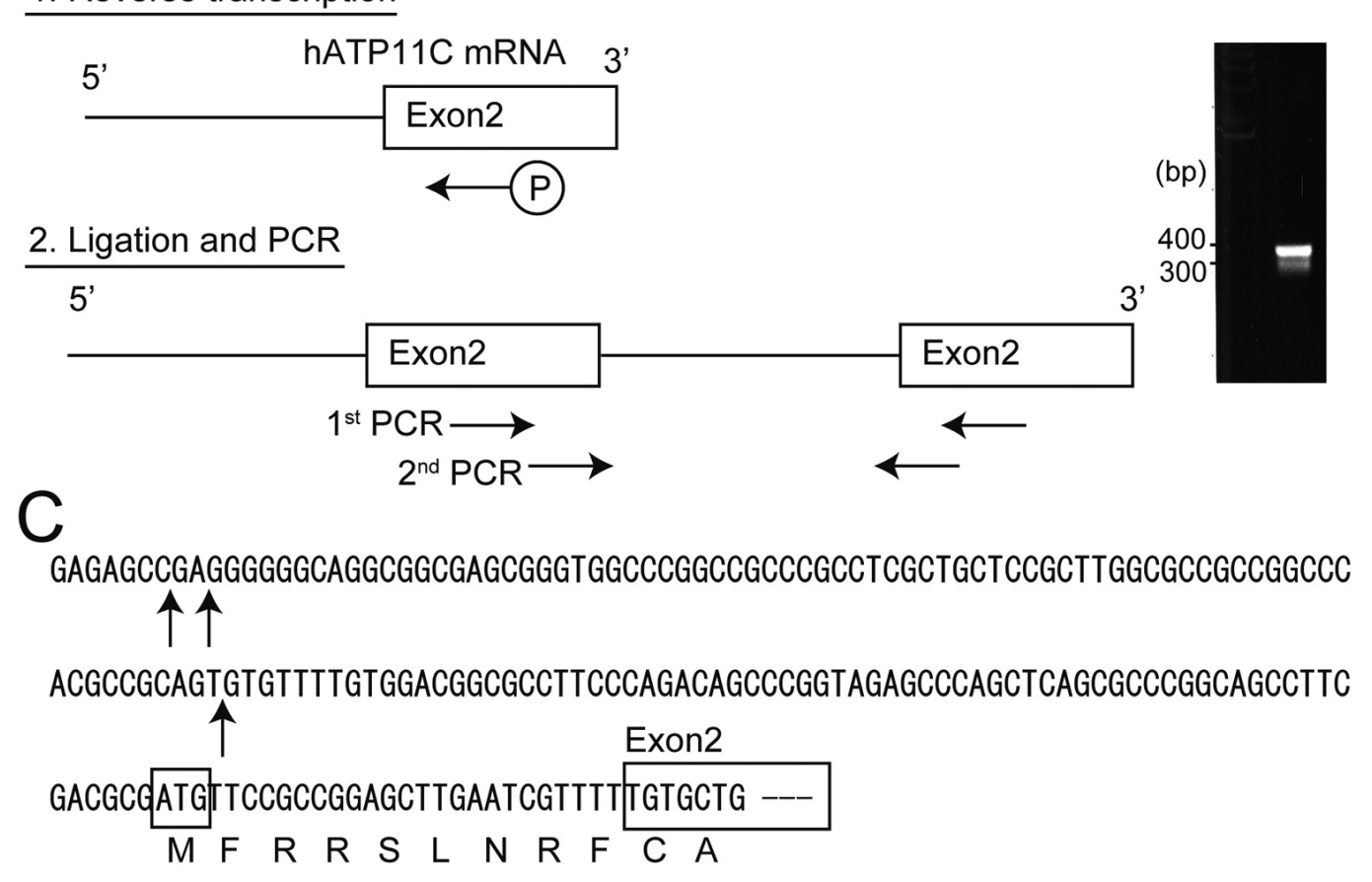

Fig. S1: The transcription initiation site for hATP11C determined by 5'-RACE-PCR.

(A) The cDNA encompassing the 5'-region of hATP 11C mRNA was prepared by reversetranscribing mRNA with a phosphorylated primer in exon 2 . The cDNA was then ligated, and used as a template for the nested PCR. Primers used for the nested PCR $\left(1^{\text {st }}\right.$ and $2^{\text {nd }}$ PCR $)$ are indicated by arrows. (B) 5'-RACE-PCR products. (C) Sequence at the 5' end of hATP11C determined by 5'-RACE-PCR. The 400-bp DNA fragment in (B) was cloned into the pGEM-T easy vector, and the DNA sequence was determined. The putative transcription initiation sites are indicated by arrows. Exon 2 and the initiation codon are indicated by boxes. 

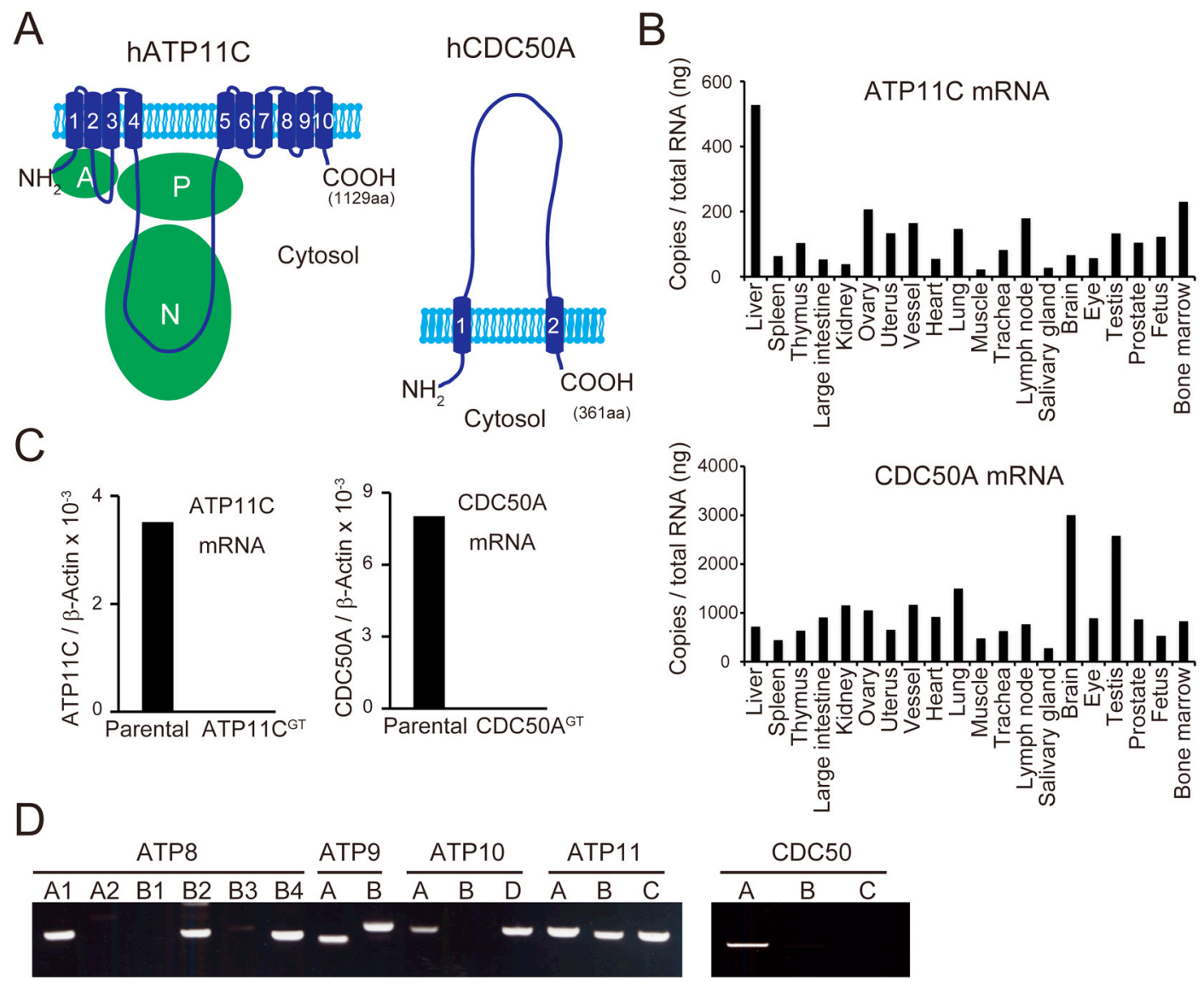

Fig. S2: Structure and expression of ATP11C and CDC50A.

(A) The structures of hATP11C and hCDC50A with transmembrane segments numbered. In hATP11C, three cytoplasmic domains (A: actuator, P: phosphorylation, and N: nucleotide binding) predicted by similarity to SERCA2a (41) are shown in green circles. (B) ATP $11 C$ and CDC50A mRNA levels in the indicated mouse tissues were determined by real-time RT-PCR, and expressed as copy numbers per ng of total RNA. (C) Real-time RT-PCR for $A T P 11 C$ and CDC50A mRNAs relative to $\beta$-actin mRNA in KBM7 (Parental), ATP11C ${ }^{\mathrm{GT}}$, and $\mathrm{CDC} 50 \mathrm{~A}^{\mathrm{GT}}$. (D) RNA from KBM7 was analyzed by RT-PCR for the indicated P4-ATPase or CDC50 family members. 
A
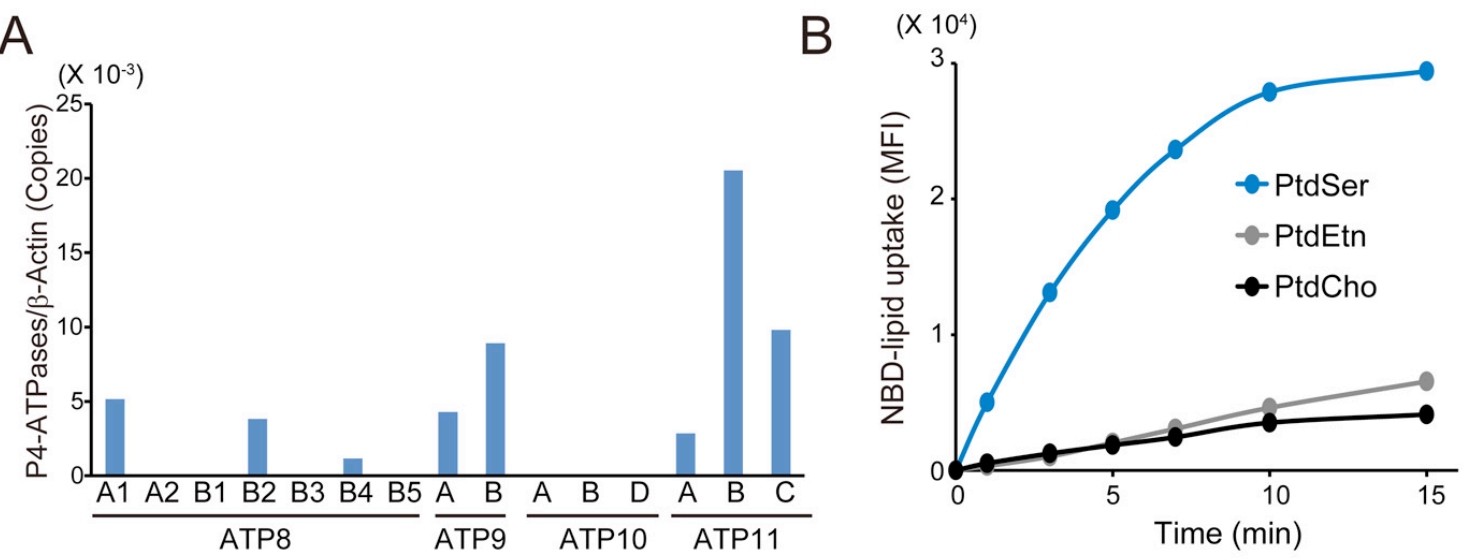

C
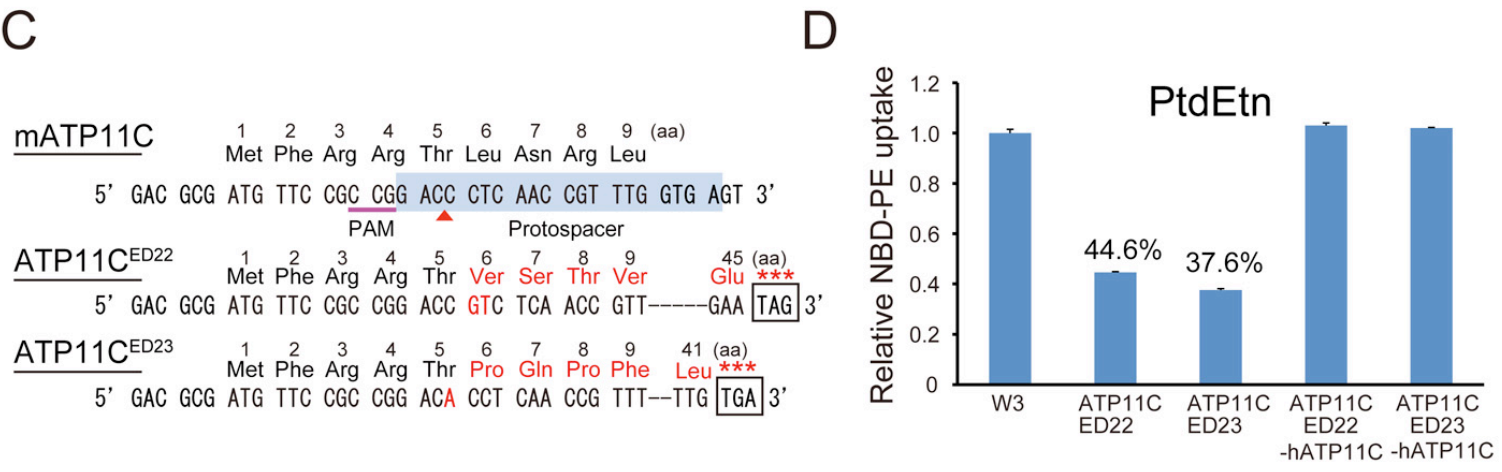

Fig. S3: Effect of $A T P 11 C$ deficiency on phospholipid incorporation.

(A) Expression of P4-type ATPase in mouse W3 cells. The mRNA level for the indicated P4type ATPases was determined by Real-Time RT-PCR, and is expressed to relative to $\beta$-actin mRNA. (B) W3 cells were incubated with 1.5 $\mu \mathrm{M}$ NBD-PS (PtdSer), NBD-PE (PtdEtn), or NBD-PC (PtdCho), treated with fatty-acid-free BSA, and analyzed by flow cytometry. The mean fluorescent intensity (MFI) is plotted. (C) Mutagenesis of mATP11C gene in W3 cells by CRISPR-Cas system. Protospacer sequence is highlighted in light blue, protospacer-adjacent motif (PAM) underlined in red, and the cleavage site with red arrowhead. The targeted ATP11C in ATP11C $C^{\mathrm{ED} 22}$ and ATP11C ${ }^{\mathrm{ED} 23}$, carrying a biallelic insertion of "GT" or "A" (in red). (D) The reduced incorporation of PtdEtn in ATP11C mutants. ATP $11 C^{\mathrm{ED}}$ mutants $\left(A T P 11 C^{\mathrm{ED} 22}\right.$ and $A T P 11 C^{\mathrm{ED} 23}$ ), and $A T P 11 C^{\mathrm{ED} 22}$ cells expressing hATP11C were incubated at room temperature for 5 min with $1.5 \mu \mathrm{M}$ NBD-PE (PtdEtn). The cells were treated with fatty-acid-free BSA, and analyzed by flow cytometry. The incorporated NBD-PE is expressed as ratio of that with W3 cells $(n=3)$. 


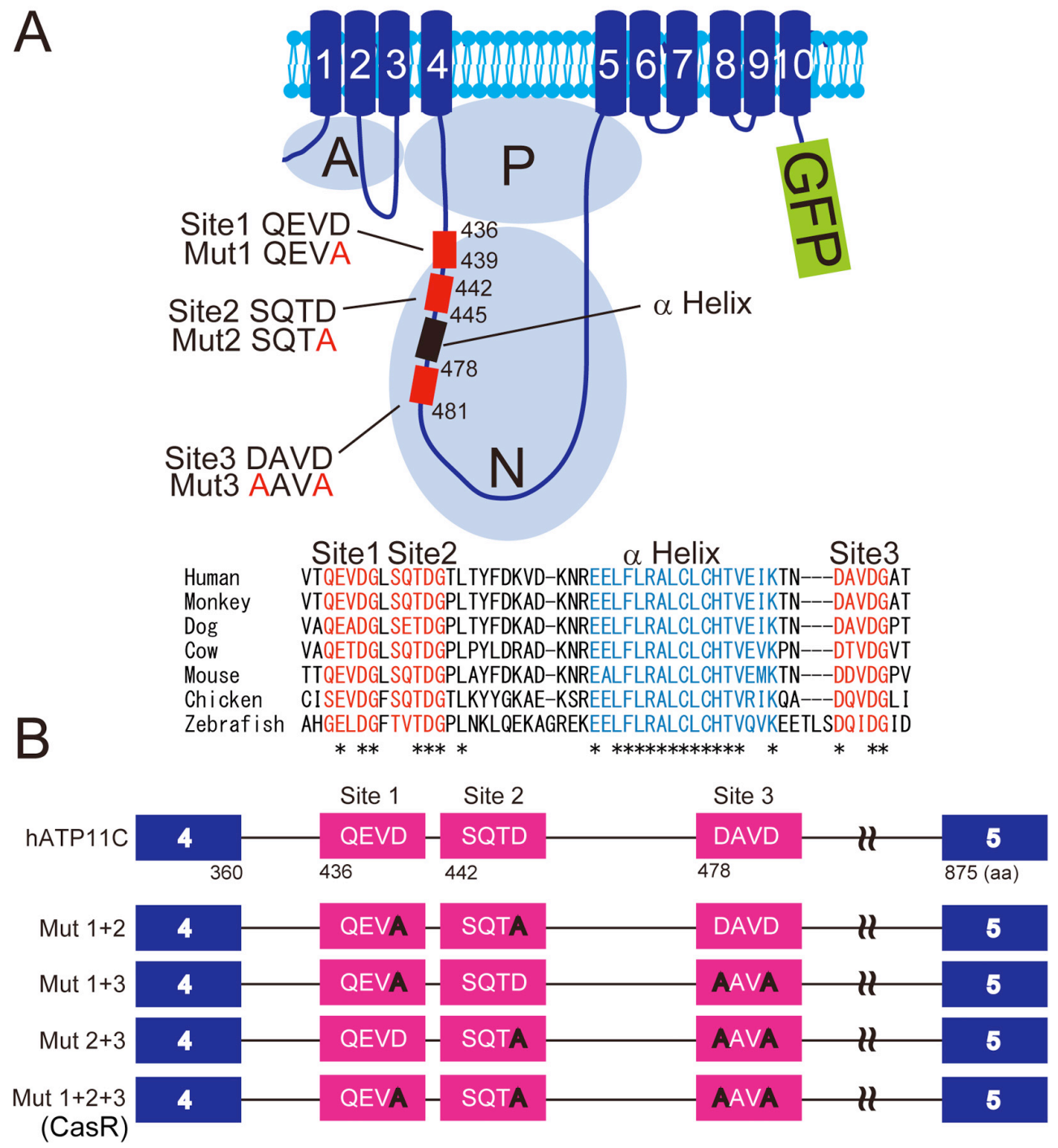

Fig. S4: The structure of ATP11C and its caspase-recognition site mutants.

(A) The structure of hATP11C-GFP with caspase-recognition sites and $\alpha$-helix boxed in red and black. The transmembrane region is numbered. The amino acid positions of the caspaserecognition site are indicated with the wild-type and mutated sequence. GFP, Green fluorescent protein. In the lower part, sequences around the caspase-recognition sites in 6 vertebrate ATP11C are aligned with * for residues conserved in all members. The caspase recognition sites were numbered as Site 1-3 from the N-terminus. (B) Schematic representation of human ATP11C caspase-recognition site mutants. At top, the three caspase-recognition sites (red boxes) located in the second cytoplasmic loop between transmembrane segments 4 and 5 (blue boxes) of hATP11C are schematically shown. In the indicated mutants, the aspartic acid residues in the caspase-recognition sites (Sites 1-3) were mutated to alanine residues. In the Mut 1+2, 1+3, and $2+3$ mutants, 2 caspase-recognition sites were mutated in different combinations, while all 3 recognition sites were mutated in the Mut $1+2+3$ mutant (CasR). 


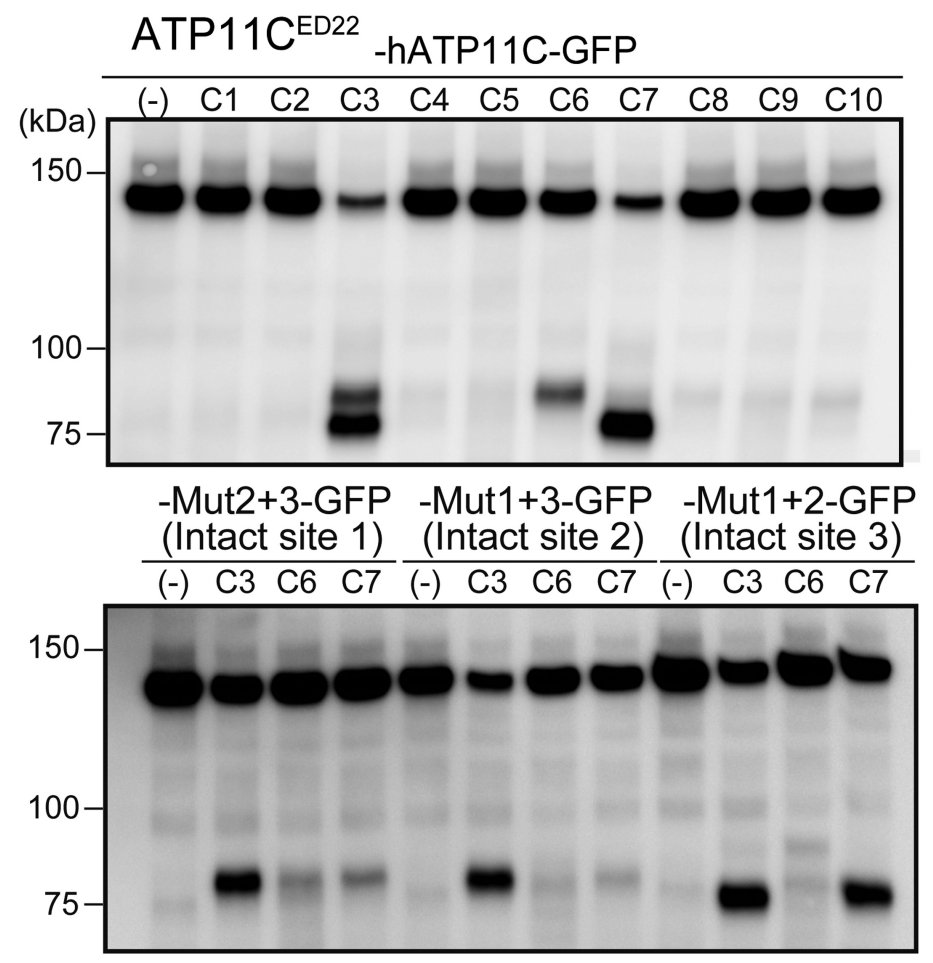

Fig. S5: Cleavage of ATP11C by caspases.

Solubilized membrane fractions of $A T P 11 C^{\mathrm{ED} 22}$ transformants expressing wild-type (upper panel) or mutant (lower panel) ATP11C-GFP were incubated with caspases (C1 to C10, caspase1-10) or untreated (-), and analyzed by Western blotting with anti-GFP. 
A

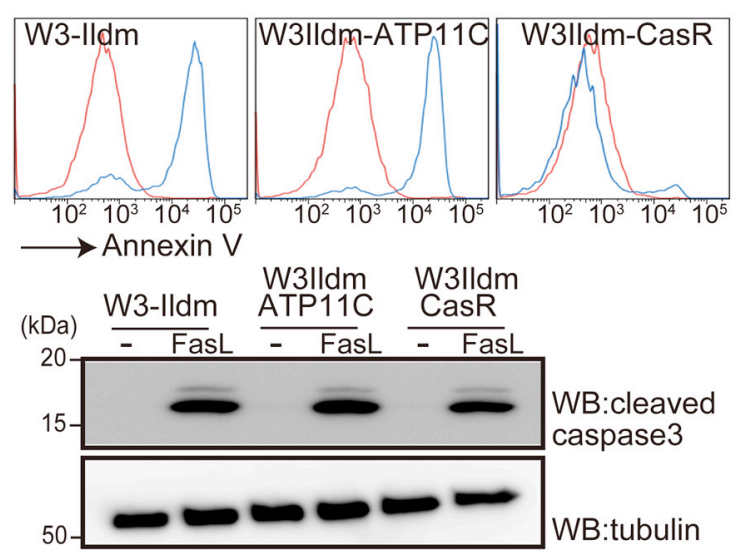

B

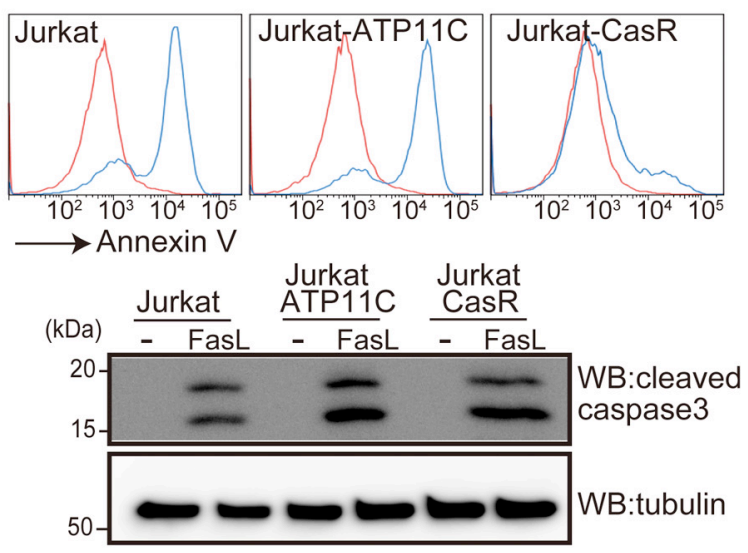

Fig. S6: Effect of the caspase-resistant ATP11C on the apoptotic PtdSer exposure.

W3-Ildm (A) and Jurkat (B) were transformed with hATP11C or CasR (W3-hATP11C, W3CasR, Jurkat-hATP11C, and Jurkat-CasR), treated with FasL for $2 \mathrm{~h}$, stained with Annexin V, and analyzed by FACS. At bottom, cell lysates were analyzed by Western blotting with antiactive caspase- 3 or anti-tubulin. 


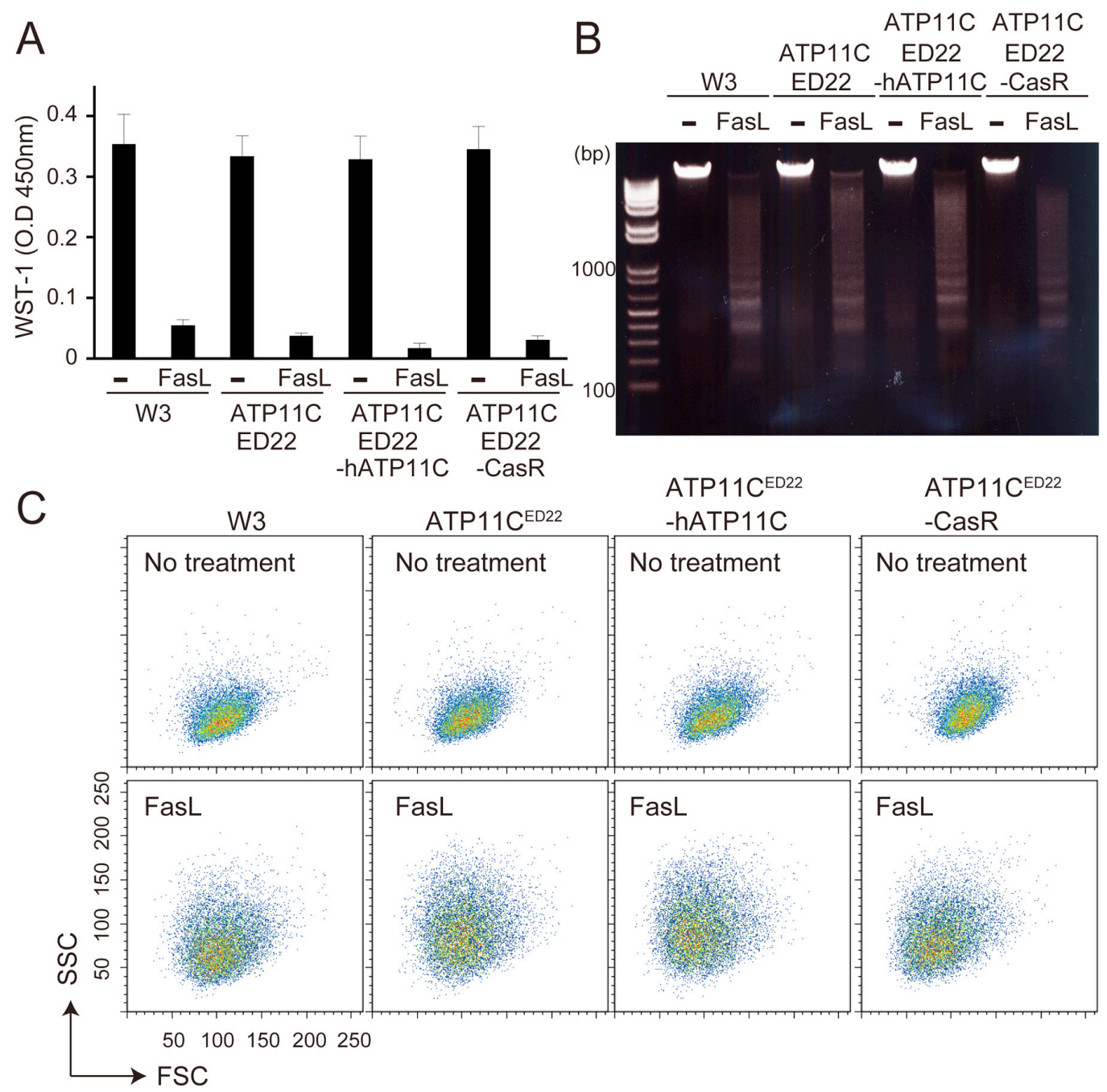

Fig. S7: No effect of the caspase-resistant hATP11C on FasL-induced cell death, DNA fragmentation, or cell shrinkage.

$\mathrm{W} 3, A T P 11 C^{\mathrm{ED} 22}$, or $A T P 11 C^{\mathrm{ED} 22}$ transformants expressing hATP11C or its caspase-resistant form (CasR) were incubated with FasL for $2 \mathrm{~h}$. (A) FasL-induced cell death was analyzed with the WST-1 assay. (B) Chromosomal DNA was prepared from untreated or FasL-treated cells, separated by electrophoresis on a $1.5 \%$ agarose gel, and stained with ethidium bromide. (C) Untreated or FasL-treated cells were analyzed by flow cytometry. The forward scatter (FSC) profile represents cell size. 

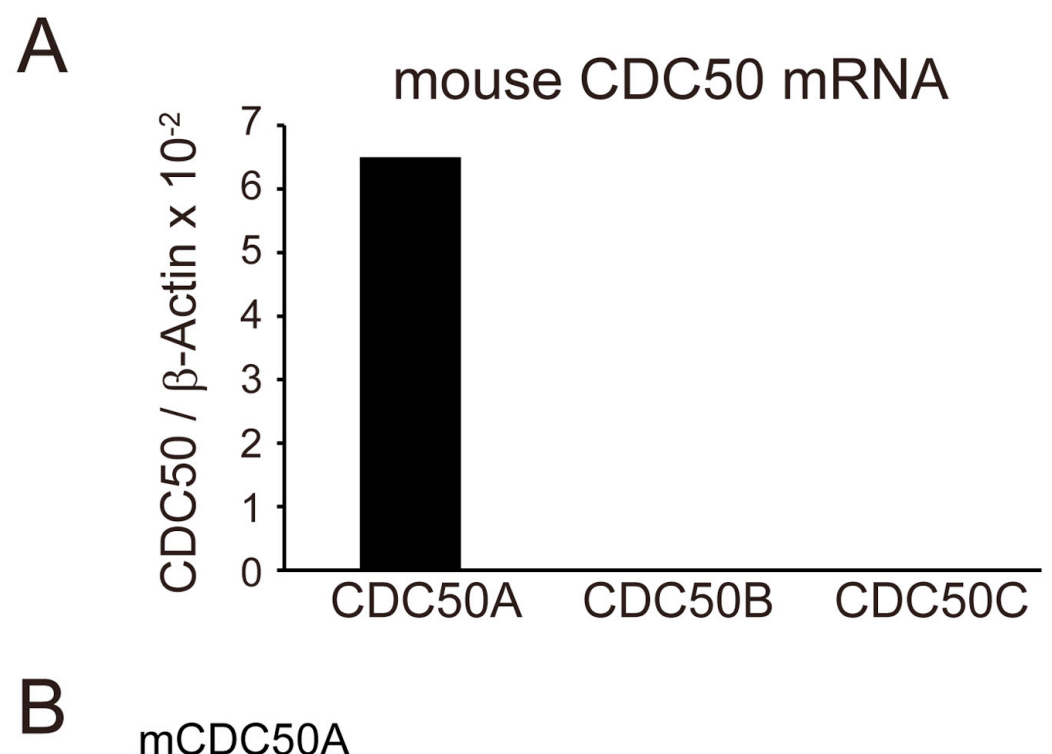

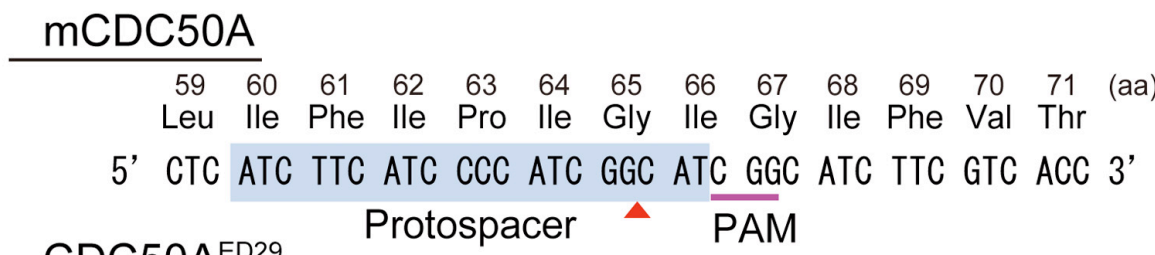

CDC50A ${ }^{\operatorname{ED} 29}$

$\begin{array}{llllllllll}59 & 60 & 61 & 62 & 63 & 64 & 65 & 66 & 67 & 76(\mathrm{aa})\end{array}$

Leu lle Phe lle Pro lle Gly His Arg Pro ***

5' CTC ATC TTC ATC CCC ATC GGG CAT CGG --- CCG TGA 3'

5' CTC ATC TTC ATC CCC ATC GCC CCA TCG

Leu lle Phe lle Pro lle Ala Pro Ser

CDC50A ${ }^{\mathrm{ED} 62}$

$\begin{array}{lllllllllll}59 & 60 & 61 & 62 & 63 & 64 & 65 & 66 & 67 & 76 \text { (аa) }\end{array}$

Leu lle Phe lle Pro lle Gly His Arg Pro ***

5' CTC ATC TTC ATC CCC ATC GGG CAT CGG --- CCG TGA 3'

5' CTC ATC TTC ATC CCC ATC GGG CCC TAT --- CAT CCG $[$ TGA 3 ,

Leu Ile Phe lle Pro lle Gly Pro Tyr

His Pro $\star * \star$

Fig. S8: Mutagenesis of CDC50A gene in W3-Ildm cells.

(A) Expression of CDC50 family members in mouse W3-Ildm cells. The mRNA level of $\mathrm{mCDC} 50$ member $(50 A, 50 B$ and 50C) was determined by Real-Time RT-PCR, and is expressed relative to $\beta$-actin mRNA. (B) Mutagenesis of $\mathrm{m} C D C 50 A$ gene by CRISPR-Cas system.

Protospacer sequence is highlighted in light blue, protospacer-adjacent motif (PAM) underlined in red, and red arrowhead for the cleavage site. Two mutated cell clones (CDC50A ${ }^{\text {ED29 }}$ and

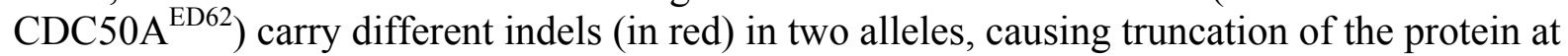
positions 76 and 99 , and 76 and 77, respectively. 


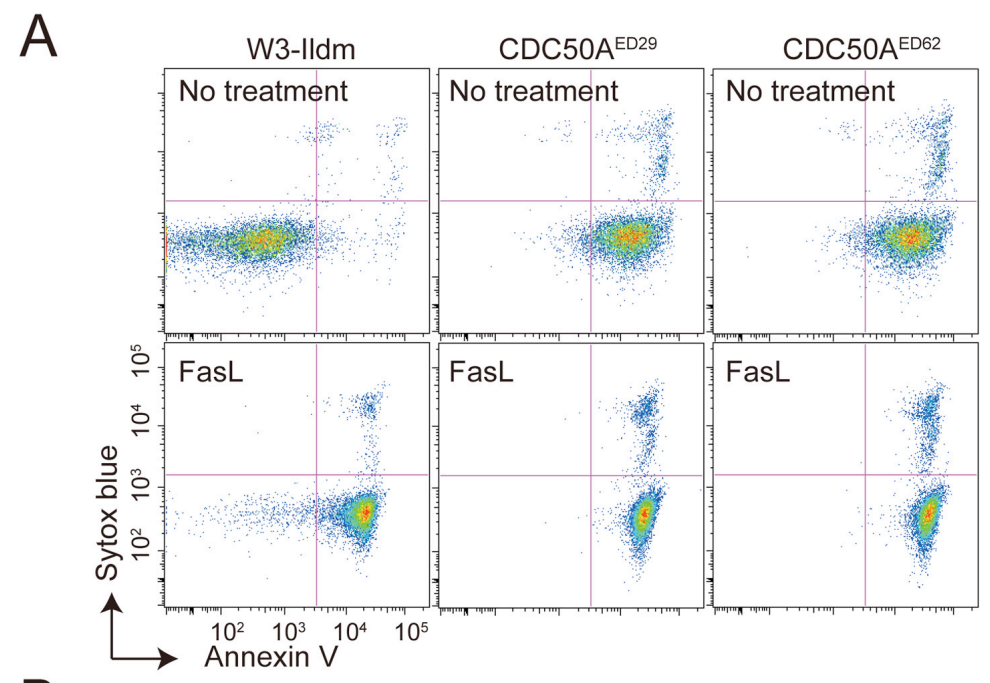

B
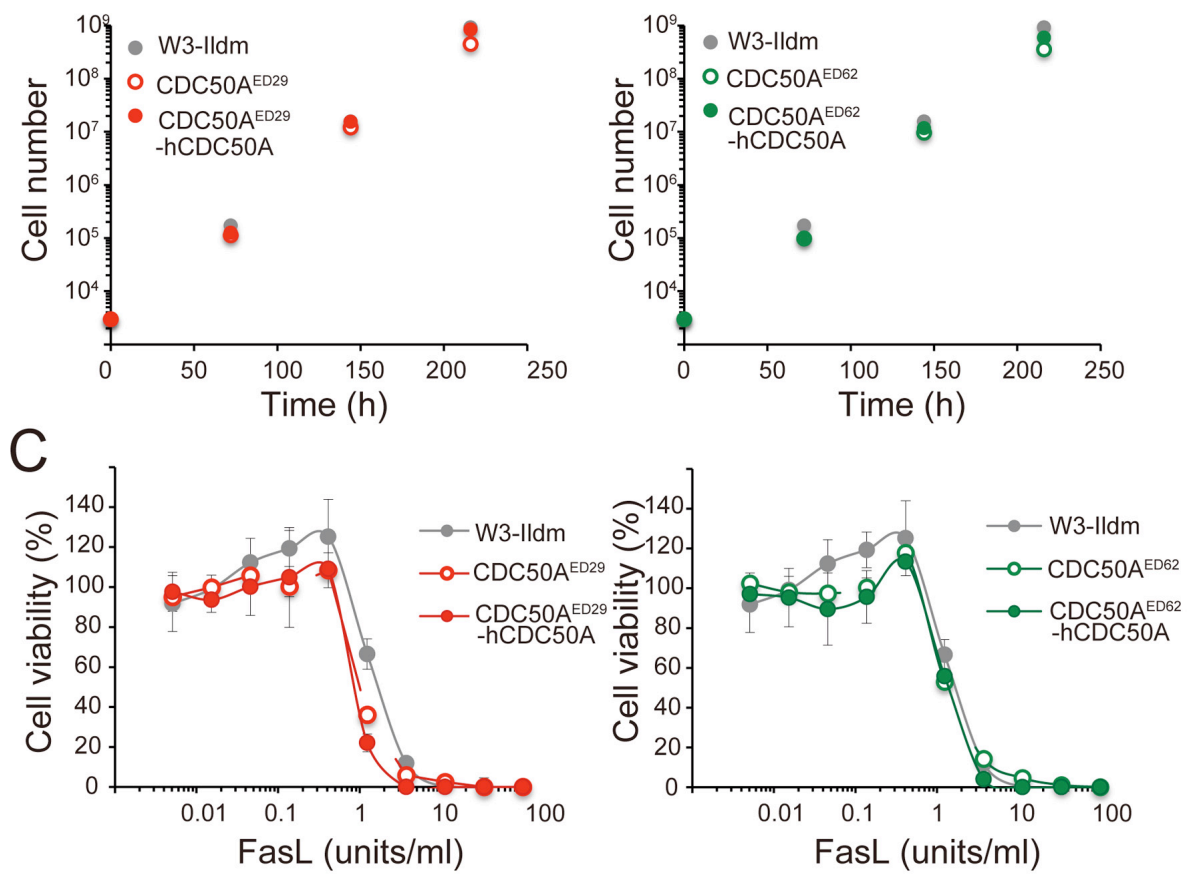

Fig. S9: PtdSer exposure in CDC50A-deficient viable cells.

(A) W3-Ildm, $C D C 50 A^{\mathrm{ED} 29}$, or $C D C 50 A^{\mathrm{ED} 62}$ cells were treated with or without FasL for $2 \mathrm{~h}$, stained with Cy5-labeled Annexin V and Sytox blue, and analyzed by flow cytometry. (B) W3Ildm, $C D C 50 A^{\mathrm{ED} 29}, C D C 50 A^{\mathrm{ED} 62}$, or their transformants expressing hCDC50A were seeded at $10^{4}$ cells $/ \mathrm{ml}$ in RPMI containing $10 \%$ FCS, and cultured. The cells were split every 3 days, and re-seeded at $10^{4}$ cells $/ \mathrm{ml}$, and their growth was followed for 9 days. (C) W3-Ildm, CDC50A ${ }^{\mathrm{ED} 29}$, $C D C 50 A^{\mathrm{ED} 62}$, or their transformants expressing hCDC50A were incubated with the indicated concentration of FasL for $4 \mathrm{~h}$ at $37^{\circ} \mathrm{C}$. The cell viability was determined with the WST-1 assay, and is expressed as the percentage of cell viability in the absence of FasL. 


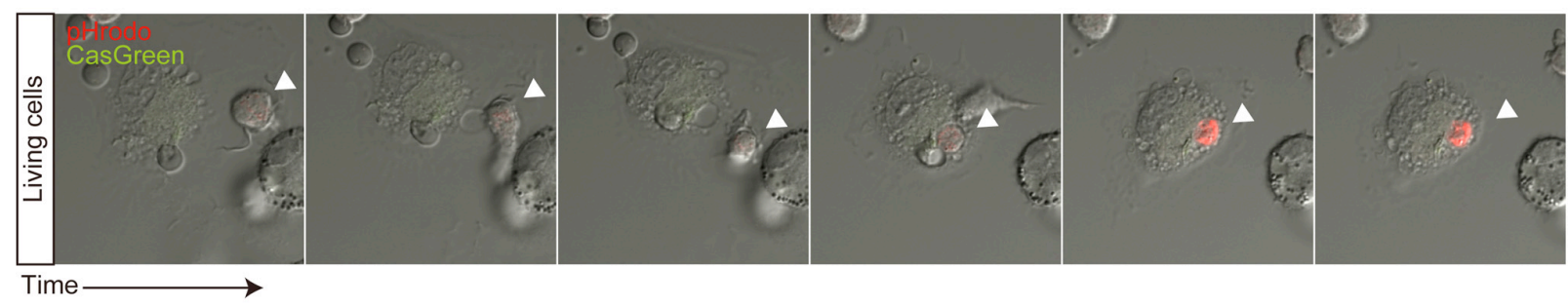

Fig. S10: Thio-pMac engulfment of PtdSer-exposing human KBM7 cells.

Thio-pMacs were incubated with pHrodo-labeled KBM7 in the presence of CellEvent ${ }^{\mathrm{TM}}$ caspase 3/7 green. The engulfment of KBM7 cells by macrophages was followed by confocal microscope. 


\section{Movie S1: Engulfment of Living $C D C 50 A^{-/-}$Cells by Macrophage.}

At the beginning, a macrophage at right side engulfs two pHrodo-labeled (pale red) and CellEvent-negative $C D C 50 A^{--}$cells, then the pHrodo-fluorescence of the engulfed cells increases, indicating that the cells were transferred to lysosomes. Then, another macrophage at left side engulfs one CellEvent-negative cell.

\section{Movie S2: Engulfment of Dead $C D C 50 A^{-/-}$Cells by Macrophage.}

A pHrodo-labeled (pale red) and CellEvent-positive (green) apoptotic $C D C 50 A^{-/-}$cell moves above a macrophage, and is engulfed. The pHrodo-fluorescence of the engulfed cells then increases, and the cell gets yellow.

\section{Movie S3: Release of Living CDC50 $A^{-/-}$Cells from Macrophage.}

A macrophage at the center engulfs a pHrodo-labeled (pale red) and CellEvent-negative $C D C 50 A^{-/-}$cell. The intensity of pHrodo fluorescence of the engulfed cells gradually increases, but suddenly the cell is released from the macrophage before transferring to lysosomes (or increasing its pHrodo-fluorescence). 